\title{
TRAZAS Y TRAZOS DE LA CIRCULACIÓN MUSICAL EN EL VIRREINATO DEL PERÚ: COPISTAS DE LA CATEDRAL DE LIMA EN SANTIAGO DE CHILE ${ }^{1}$
}

\author{
TRACKS AND TRACES OF THE MUSICAL CIRCULATION IN THE \\ VICEROYALTY OF PERU: COPYISTS FROM LIMA CATHEDRAL IN \\ SANTIAGO DE CHILE
}

\author{
Alejandro Vera Aguilera \\ Instituto de Música Pontificia Universidad Católica de Chile
}

\begin{abstract}
Resumen:
El presente trabajo busca ampliar el conocimiento actual sobre la circulación musical en el virreinato del Perú por medio de un estudio comparado entre las partituras del período colonial que se han conservado en las catedrales de Lima y Santiago de Chile. De esta forma, se establecen nuevas correspondencias tanto musicales como caligráficas, demostrándose que algunas de las obras conservadas en Santiago fueron copiadas en la capital del virreinato; se formulan hipótesis convincentes acerca del posible origen español de ciertas fuentes musicales; y se realizan aportaciones metodológicas para el estudio de los copistas de música, que complementan las ya existentes. Finalmente, el trabajo permite cuestionar importantes premisas sobre la vida musical de la catedral de Lima que nos han sido transmitidas en trabajos previos.
\end{abstract}

\section{Palabras clave:}

Circulación musical, copistas de música, época colonial, virreinato del Perú, catedrales de Lima y Santiago de Chile.

\begin{abstract}
:
This article seeks to expand the current knowledge about the circulation of music in the Viceroyalty of Peru, through a comparative study between music scores from the colonial period that have been preserved in the cathedrals of Lima and Santiago de Chile. Contributing with new musical and calligraphic concordances, it shows that some of the works held in Santiago were copied in the viceregal capital. It also raises convincing hypotheses about the possible Spanish origin of certain musical sources, as well as methodological contributions for the study of music copyists, complementing the existing ones. Finally, it goes on to question important assumptions about the musical life of Lima cathedral that have been transmitted in previous works.
\end{abstract}

Key words:

Circulation of music, music copyists, colonial period, viceroyalty of Peru, cathedrals of Lima and Santiago de Chile.

1 Este trabajo ha sido escrito en el marco del proyecto Fondecyt 1100650. Quisiera agradecer a la dirección y personal del Archivo de la Catedral de Santiago (Chile), el Archivo Arzobispal de Lima y el Archivo de la Catedral de Lima por su ayuda durante mis investigaciones. 
¿Pero por qué no habríamos de reconocer nuestras reconstrucciones cronológicas como lo que son, hipótesis? ¿Y por qué los historiadores de la música -más que los físicos o matemáticos - habrían de sentirse avergonzados por tener que reemplazar las hipótesis que han sobrevivido a su utilidad? (Arthur Mendel). ${ }^{2}$

El punto es si una frase descriptiva [...] puede estar libre de connotaciones de valor. ¿Podemos decir "estilo clásico maduro" sin que ello implique un estadio musical superior al sugerido por "estilo clásico temprano"? Ciertamente no, pues todas las afirmaciones de este tipo están apoyadas por una teoría de la historia que impone una jerarquía a sus sujetos (Leo Treitler). ${ }^{3}$

\section{EL ESTUDIO DE LOS COPISTAS DE MÚSICA}

Hace un tiempo, buscando información en Internet sobre el tema general de este artículo, me topé con un bello cuento del escritor norteamericano Spencer Holst titulado, justamente, "El copista de música". En él relata la historia de un copista activo en Manhattan, probablemente en la década de 1960, que acaba de terminar un trabajo urgente para un famoso intérprete de viola. Cuando concurre a su casa en Long Island, a fin de entregarle personalmente el material que ha preparado, éste le invita a pasar a una fiesta que está celebrando. En ella se encuentra la alta sociedad musical del momento y el copista se siente algo fuera de lugar, considerando sus manchas de tinta en los pulgares y el traje corriente que lleva. Pasado un tiempo, el maestro llama la atención de sus invitados sobre una colección de programas de concierto que posee, de gran valor histórico: en las paredes de su estudio se encuentran enmarcados programas originales de Paganini, Casals y otras leyendas de la música. Entonces el copista comenta que él también tiene en su poder un programa valioso de un concierto muy especial que presenció en Octagon, Ohio. Orgullosamente, exhibe a la concurrencia el ejemplar mimeografiado que lleva en su bolsillo. Luego, a petición del anfitrión, pasa a explicar de qué se trata: hace varios años asistió a un concierto a cargo de un coro y una orquesta de niños de una academia, en el que tocaba flauta dulce el hijo menor de una prima; el concierto se desarrollaba discretamente cuando, poco antes de terminar, la directora anunció que, en lugar de las dos canciones de Vivaldi que estaban programadas, tocarían íntegramente la Pasión según San Mateo de Johann Sebastian Bach; cuando el copista todavía no salía de su incredulidad, los organizadores repartieron al público unos gorros de papel que brillaban en medio de la oscuridad, bajo el efecto de una luz especial, produciendo, con las cabezas de los asistentes, una cruz blanca con fondo azul; entonces comenzó la ejecución, en un escenario que también había sido oscurecido y en el cual solo se veían las túnicas marrones de los ejecutantes; pero, para su sorpresa, ya no tocaba la misma agrupación, sino una excelente orquesta con instrumentos "originales"; pasado un tiempo, el copista, gracias a un raro talento que le permitía detectar a casi cualquier intérprete que hubiese oído con anterioridad, identificó a

2 1960: 300. De no indicarse lo contrario, las traducciones al castellano son mías.

3 1989: 92. 
un cornista francés a quien conocía y creía haber visto en Octagon ese día; terminada la función, se dirigió al camarín a felicitarle por el maravilloso espectáculo que él y los demás músicos habían ofrecido, pero la directora le impidió el paso; finalmente, a las dos de la mañana, se marchó con su prima de vuelta a casa. Una vez terminada su historia, y para ponerle el broche de oro, el copista vuelve a exhibir triunfante el programa de dicho concierto, mostrando las dos canciones de Vivaldi que figuran al final. Pero, para su sorpresa, nadie parece haberle creído: solo recibe miradas de duda y comentarios despectivos, incluyendo uno hiriente del maestro de viola. Ante la incomodidad decide marcharse. Pero, cuando está saliendo de la casa, el maestro de viola se le acerca discretamente y le pide que le permita acompañarle un trecho. Entonces se excusa por el comentario que "tuvo que decir" ante sus invitados; y luego reconoce, visiblemente emocionado, que esa noche en Octagon fue estupenda y que lo sabe porque él también estaba allí, tocando la segunda viola. ${ }^{4}$

No obstante ser una historia de ficción, el cuento de Holst es pertinente aquí porque da cuenta de la distancia social e intelectual que supuestamente debería existir -e históricamente ha existido $-{ }^{5}$ entre un auténtico maestro de música y un copista, o dicho de otra forma, entre un verdadero artista y un artesano. El violista sabe que la historia del copista es cierta, pero no puede reconocer ante sus pares que comparte dicha vivencia con él ni menos concederle protagonismo en medio de su propia fiesta. Así mismo, nadie da crédito a la habilidad musical que el copista se atribuye, pues se supone que un talento como ése solo está reservado a los músicos propiamente dichos.

Esta diferencia de estatus social se ha transformado en el campo de la musicología en una diferencia de estatus historiográfico; es decir, ha hecho que el copista sea considerado mucho menos importante que el compositor o el intérprete como sujeto (y fuente) para la historia de la música. Esto en modo alguno quiere decir que los estudios sobre copistas de música sean inexistentes, como irá quedando claro a medida que transcurra este trabajo, pero sí que su número es infinitamente menor al de los estudios dedicados a los intérpretes y, especialmente, los compositores. Con razón Barry S. Brook y Marvin E. Paymer se quejaban, aún en 1982, de lo poco que se había publicado "sobre el análisis comparativo de las caligrafías musicales" y de que no se hubiese desarrollado "ningún método sistemático para el análisis caligráfico de la música". ${ }^{6}$ Hoy en día, salvo alguna excepción, ${ }^{7}$ podemos afirmar que el vacío en términos de nuevas propuestas metodológicas es prácticamente el mismo.

Pero la diferencia de estatus comentada ha incidido incluso en los propios trabajos sobre copistas de música, que hasta hace no mucho tiempo se concentraron preferentemente en autógrafos de (grandes) compositores. Y no se trata de poner en duda su importancia, pero sí de advertir sobre los peligros de atenerse

4 El cuento figura en HOLST, 1995. Está disponible en http://es.scribd.com/doc/51733043/20/El-copista-de-musica, consultado el 21-10-2011.

5 El bajo estatus social de los copistas de música se remonta a la Edad Media -véase BOORMAN, 2001.

6 BROOK y PAYMER, 1982: 551.

7 Me refiero a la tesis doctoral de Martin Jarvis, quien propone aplicar los principios del análisis científico ("forense") de la caligrafía textual a la escritura musical -véase JARVIS, 2007. Adicionalmente, Vitaly Feldman y Matthias Roeder se encuentran desarrollando un software de reconocimiento de copistas de música, el cual aún se encuentra en fase prueba. Hay información sobre el proyecto en http://www.scribeproject.org/bin/view/Main/ProjectDescription, consultado el 21-10-2011. 
exclusivamente a ellos. Cliff Eisen lo ha demostrado en relación con la obra de Mozart: los responsables de su última edición íntegra -la Neue Mozart-Ausgabe (NMA) - al verse enfrentados a la desaparición de una centena de originales del compositor, ocurrida durante la Segunda Guerra Mundial, decidieron basar sus transcripciones preferentemente en un grupo de manuscritos de la primera mitad del siglo XIX, porque supuestamente se trataba de copias fidedignas de los autógrafos que se habían perdido; de ese modo, relegaron a un segundo plano muchas copias manuscritas y algunos impresos gestados en el siglo XVIII. La hipótesis era que, al ser copias de autógrafos realizadas por musicólogos, las versiones de principios del XIX tendrían menos errores que las copias dieciochescas. El prestigio de los autógrafos pareció hacer innecesario el estudio detallado de las copias contemporáneas a Mozart realizadas por copistas profesionales. Pero Eisen demuestra que estas últimas son con frecuencia más confiables en aspectos como el uso de las articulaciones en las cuerdas y la resolución de algunas disonancias. Esto se debe a que tales copistas trabajaban en Salzburgo al servicio del compositor y conocían mejor su estilo que los musicólogos posteriores. ${ }^{8}$

Si los copistas que trabajaron junto a los compositores fueron descuidados, podemos imaginar lo que ocurrió con aquellos que se hallaban lejanos al contexto de creación de la obra, ya fuese desde el punto de vista temporal o geográfico. Sin embargo, sus copias y las variantes que contienen nos hablan con frecuencia de un contexto particular de ejecución que puede ser legítimo y digno de estudio. Tanto así que en ciertos repertorios y obras más "abiertos" el propio compositor puede haber estado consciente de que tales variantes serían introducidas. En el caso del canto llano, por ejemplo, las distintas órdenes religiosas realizaban modificaciones a las melodías originales, que pasaban luego a constituir rasgos de su propia identidad musical. ${ }^{9}$

Suele olvidarse también que, a diferencia del protagonista del cuento de Holst, los copistas tenían con frecuencia conocimientos musicales avanzados, especialmente en la época que nos ocupa. Exceptuando algunas capillas nobiliarias y quizás las catedrales más importantes, donde podemos encontrar copistas que cumplían exclusivamente esta función, ${ }^{10}$ en la mayor parte de las instituciones se trataba de un maestro de capilla, cantor o instrumentista que asumía esta tarea entre muchas otras. Estos copistas-músicos se parecían con mucha frecuencia a un editor, pues introducían las enmiendas o indicaciones de interpretación que consideraban apropiadas; ${ }^{11}$ al punto de que se ha afirmado que es erróneo limitar el concepto de edición a la música impresa, pues los copistas de Viena, en la segunda mitad del siglo XVIII, operaban en equipos que funcionaban como verdaderas editoriales, distribuyendo la música a gran escala. ${ }^{12} \mathrm{Si}$ actualmente se ha aceptado que en toda edición interactúa la autoría del compositor con la del editor, ${ }^{13}$ debería aceptarse también que en un alto porcentaje de música manuscrita interactúa la autoría del compositor con la del copista.

Considerando lo anterior, no es extraño que algunos personajes de la historia de la música que durante mucho tiempo habían sido considerados como "meros" copistas se eleven de pronto a la categoría

8 EISEN, 1991: 514-519.

9 GRIER, 2008: 53, 66, 94, 105-109.

10 Un buen ejemplo lo constituye la Capilla Real de Madrid, cuyos copistas de música han sido bastante estudiados, sobre todo a comienzos del siglo XVIII -véase TORRENTE, 2002: 49-51.

11 BOORMAN, 2001.

12 EDGE, 1998: 303.

13 GRIER, 2008: 12. 
de compositores. El ejemplo más reciente y controversial se debe a Martin Jarvis, quien propone en su tesis doctoral que Johann Sebastian Bach no es el compositor de las famosas suites para chelo BWV 1007-1012 y que es muy posible que su segunda esposa, Anna Magdalena Wilcken, sea quien las compuso. Hasta ahora, ella era ampliamente conocida como copista de obras de Bach. ${ }^{14}$ Pero Jarvis propone que su manuscrito de dichas suites no es realmente una copia deficiente de un autógrafo perdido de su marido, como hasta ahora se pensaba, sino una "obra en proceso", es decir, un autógrafo de la propia Anna Magdalena, quien trabajaba como cantora e instrumentista en la corte de Cöthen y pudo por tanto estar instruida en el arte de la composición. ${ }^{15}$ Esto explicaría no solo los errores significativos que dicho manuscrito contiene, sino también algunos rasgos de las suites que parecen ajenos al estilo bachiano. Si bien los argumentos de Jarvis no son concluyentes, es un hecho que muchos compositores -el propio Bach entre ellos- ${ }^{16}$ se desempeñaron a la vez como copistas de sus propias obras y de las de otros compositores. Volveremos a ello cuando hablemos de las fuentes musicales conservadas en Lima.

\section{ALGUNOS PROBLEMAS METODOLÓGICOS}

De lo dicho hasta aquí se desprende que el estudio de los copistas de música es una tarea que conlleva no pocos problemas. Uno de ellos se nos presenta como una moneda de dos caras. Por un lado, los copistas solían trabajar con colaboradores: así lo hicieron, por ejemplo, Francisco Lizondo, copista de la Real Capilla en la segunda mitad del siglo XVII o Wenzel Schlemmer, copista favorito de Beethoven. ${ }^{17}$ Frecuentemente esta colaboración ocurría de a pares: un copista principal tenía a un discípulo a su servicio, a quien había enseñado caligrafía, por lo cual la escritura de ambos resulta hoy difícil de distinguir. ${ }^{18}$ Para aumentar el lío, las manos del texto y la música no siempre eran la misma: Paul Laird afirma que en algunos villancicos españoles de comienzos del siglo XVIII, conservados en El Escorial, el texto fue copiado por un copista y la música por otros dos. ${ }^{19}$ Por lo tanto, una cara de la moneda consiste en que lo que a primera vista, en un corpus de manuscritos musicales amplio, puede llegar a parecernos un "copista x", podría corresponder en realidad a dos o más copistas.

Por otro lado, un mismo copista puede presentar diferencias significativas de un manuscrito a otro. En esto suelen influir el estrés, la prisa y el paso del tiempo, que parece afectar especialmente al trazo. ${ }^{20}$ Un copista puede también variar su caligrafía voluntariamente, para imitar la de su original; esto suele

14 Véase una síntesis en TOMITA, 2007: 60-65.

15 JARVIS, 2007: 54, 58, 110-156, 190-352.

16 TOMITA, 2007: 64.

17 Véase RODRÍGUEZ, 2003: 228, y TYSON, 1970: 441-442.

18 A mediados del siglo XX se logró individualizar a un copista de Bach que durante mucho tiempo se había confundido con el propio compositor -véase MENDEL, 1960: 295. Años después, fue identificado por Andrew Talle como un alumno suyo, Bernhard Christian Kayser (1705-58) -véase TOMITA, 2007: 71.

19 LAIRD, 1986: 262-263.

20 TYSON, 1970: 443. Cf. JARVIS, 2007: 81. 
ocurrir cuando se copia a partir de un libro impreso que se considera de valor, ${ }^{21}$ o cuando existe un respeto especial hacia las fuentes musicales del pasado. ${ }^{22}$ Así mismo, la caligrafía puede modificarse cuando se pasa de un formato a otro: no es lo mismo un borrador que las partes en limpio a partir de las cuales tocarán los músicos. ${ }^{23}$ En otros casos el uso de una pluma o un tipo de tinta distintos a lo acostumbrado puede dar la impresión de otra caligrafía. ${ }^{24}$ Por si esto fuese poco, algunos copistas acostumbran, sin que parezca haber una razón especial, a variar rasgos de su escritura que podríamos suponer muy estables, como por ejemplo las claves. ${ }^{25}$ Por lo tanto, la otra cara de la moneda es que si uno hila demasiado fino puede llegar a identificar como varios copistas lo que en realidad corresponde a uno solo.

La búsqueda de un equilibrio entre estos dos polos constituye un problema mayúsculo para el estudio de la caligrafía musical. Pero, para que no cunda el pánico, habría que reconocer que estos dos tipos de error no necesariamente invalidan las conclusiones de un estudio, al menos en términos generales. Por ejemplo, el hecho de confundir a Schlemmer con el "copista B" de Beethoven, como lo llama Tyson, ${ }^{26}$ podrá ser un error, pero posiblemente no impida al estudioso vincular el corpus de partituras copiadas por ambos con el círculo más estrecho del compositor y validarlas como fuentes confiables para una eventual edición; esto porque una similitud caligráfica extrema suele indicar que los copistas pertenecían a un mismo contexto institucional.

Siguiendo esta misma lógica, una diferencia caligráfica abismal entre dos copistas de un mismo corpus pudiera llegar a indicar que éste se gestó en dos instituciones o lugares diferentes, punto que será igualmente relevante para nuestro análisis posterior. Esto ocurre frecuentemente cuando una pieza ha sido enviada de una institución a otra y los copistas de la institución receptora han vuelto a copiar algunas de las partes, para luego guardar todo en un mismo legajo, ${ }^{27}$ pero incluso un libro de música encuadernado y de aspecto relativamente homogéneo puede haber sido elaborado en base a materiales copiados por distintas manos y en distintos centros. ${ }^{28}$ Así, lo que a ojos del investigador aparecerá como un corpus único de fuentes musicales puede haber correspondido originalmente a dos corpus de distinta procedencia. Desde luego, cualquier hipótesis en este sentido debería contrastarse con información complementaria, pues también es posible que dos copistas con una caligrafía muy distinta trabajasen juntos en una misma institución.

Otro problema importante consiste en individualizar e identificar a un copista. Se trata de términos distintos, aunque frecuentemente se confundan. Con el primero me refiero a establecer la caligrafía textual

21 Véase un ejemplo en MARÍN LÓPEZ, 2007: 447.

22 Como el que los copistas de Moxos de los siglos XIX y XX sentían por las fuentes musicales de la colonia-véase ARCE, 2011: 150, 153 .

23 Sin embargo, las diferencias tampoco deberían ser tantas, pues nunca hay una línea divisoria tan clara entre uno y otro estilo -JARVIS, 2007: 175-176.

24 Obviamente, el hecho de que dos copistas compartan ambos elementos puede generar la impresión inversa -véase TOMITA, 2007: 66 .

25 Anna Magdalena Bach empleaba tres tipos de claves de Do -véase JARVIS, 2007: 181-184.

26 TYSON, 1970: 450.

27 Hay ejemplos en MARÍN, 2002: 258-262.

28 Por ejemplo, si mi hipótesis sobre el "Libro de tonos humanos" de la Biblioteca Nacional de España (M. 1262) es correcta, el carmelita Diego Pizarro incluyó en su manuscrito algunos fascículos que había realizado previamente un copista de la corte de Madrid -véase VERA, 2002: 31-42, 64-69. 
y musical que corresponde a un copista en particular, pero sin saber aún de quién se trata. ${ }^{29}$ Identificarlo, en cambio, equivale a ponerle nombre y apellido..$^{30}$

En el intento por individualizar a un copista, quizás la primera pregunta sea qué rasgos de su caligrafía musical debemos observar. La respuesta que primero viene a la cabeza es "todos", dado que tanto aquellos más elementales como los más complejos contribuyen a caracterizar al personaje. Sin embargo, una cosa es que el estudioso llegue a la convicción de haber individualizado a un copista y otra muy distinta que sea capaz de convencer a otros de que sus conclusiones son correctas; sobre todo porque "la evaluación final que siga a una investigación, comparación o examen de muestras caligráficas, especialmente cuando son muy similares, será siempre materia de opinión". ${ }^{31}$ Se trata pues, como tantas otras veces en musicología, del juicio crítico que un investigador -ojalá bien informado- emite a partir de la evidencia disponible, antes que de una verdad en términos absolutos. ${ }^{32}$

Por esta razón es inevitable priorizar algunos rasgos, si no para el análisis, al menos para la presentación de los resultados ante los lectores. Brook y Paymer, basándose en la metodología científica o "forense" para el análisis caligráfico, distinguen entre rasgos primarios -aquellos que caracterizan más claramente al copista en cuestión- y segundarios -aquellos que "son o bien demasiado variables o muy ampliamente usados para merecer su inclusión". Así, en su análisis de los copistas de los manuscritos de Pergolesi se fijan primordialmente en las claves, los accidentes, las cifras indicadoras, las semicorcheas y las indicaciones de interpretación, mientras que consideran como secundarios los silencios y las negras, entre otros..$^{33}$

Walter Emery distingue la mano de Anna Magdalena Bach de la de su marido basándose en el tratamiento de las claves de Do, las plicas descendentes, la densidad del trazo, las cifras indicadoras y el tratamiento de la figura rítmica compuesta por una corchea con puntillo y una semicorchea. ${ }^{34}$

Alan Tyson toma en cuenta además las llaves que agrupan los sistemas al inicio, las dinámicas, los silencios, el "colofón” (signo empleado para cerrar una obra o sección), las barras de compás y los accidentes..$^{35}$

Jarvis, por su parte, concentra su atención en las cifras indicadoras, los títulos de movimientos, las claves y la "notación musical general". El concepto fundamental que orienta su selección proviene de la metodología científica de análisis caligráfico y es el de la complejidad. Al igual que los autores anteriores, las claves (particularmente la de Do) le parecen los elementos más apropiados para individualizar una mano determinada porque, al ser más complejos, en teoría resultan menos susceptibles de grandes cam-

29 El diccionario en línea de la Real Academia Española apunta las siguientes definiciones del término que resultan aplicables aquí: "especificar algo, tratar de ello con particularidad y por menor"; y "expresar algo con todas sus circunstancias y particularidades". Véase www.rae.es, consultado el 30-11-2011. Schlemer.

30 Tyson, por ejemplo, en su estudio citado, primero individualiza al "copista A" de Beethoven y luego lo identifica como

31 JARVIS, 2007: 108.

32 Aparte de los trabajos citados de Treitler y Grier, véase RAMOS LÓPEZ, 2003: 36.

33 BROOK y PAYMER, 1982: 552, 570.

34 EMERY, 1953, citado por TOMITA, 2007: 68.

35 TYSON, 1970: 444-445, 459, 463. 
bios y más difíciles de imitar. Las plicas y otros elementos similares le parecen más simples y por tanto menos relevantes si se toman aisladamente. ${ }^{36}$

Sin poner en duda la contundencia del aporte de Jarvis en su conjunto, esto último me parece discutible. Los elementos más simples son aquellos que se realizan de manera más inconsciente (otro aspecto importante para la metodología que él describe), por lo cual podrían reflejar mejor la caligrafía particular y espontánea de un copista. En este sentido, me es inevitable recordar al crítico de arte decimonónico Giovanni Morelli, cuyo método hizo célebre el historiador Carlo Ginzburg muchos años después, al considerarlo como un antecedente para su paradigma "indiciario" o conjetural de investigación. El método usado por Morelli para atribuir las obras de arte consistía en prestar atención a rasgos en principio insignificantes en el cuadro (por ejemplo, el diseño de las uñas) y no a los más llamativos o característicos, ya que eran estos últimos los que los falsificadores intentarían imitar. ${ }^{37}$

De lo anterior se desprende que los rasgos a considerar no necesariamente deben ser los mismos para todos los copistas y, también, que resultaría peligroso concentrarse en ciertos rasgos a priori, sobre todo cuando se trabaja con un corpus heterogéneo de fuentes como el que nos ocupará aquí. Retomando la idea de Brook y Paymer, una llave de Sol podría resultar primaria para un copista pero secundaria para otro. Así mismo, los rasgos prioritarios a observar dependerán de la época y el estilo. Por ejemplo, las indicaciones de interpretación pueden ser menos relevantes para el siglo XVII que para el XIX, dada la frecuencia con que aparecen y su variedad; y en una pieza vocal las corcheas sueltas quizás tengan mayor importancia que en una instrumental. En concordancia con estas ideas, durante el trabajo de individualización de copistas que presentaré más adelante he considerando tanto rasgos muy elaborados como otros más simples, sin que necesariamente fuesen los mismos para todos ellos.

El trabajo de identificación no resulta menos complicado. Como veremos, las anotaciones en las cuales el copista se atribuye explícitamente la elaboración de un manuscrito suelen ser muy escasas y, aun cuando lo hace, no está de más verificar que ésta sea efectiva, comparando la caligrafía de la anotación con la de la fuente musical en su conjunto. Por lo general, en el mejor de los casos hallaremos alguna firma o rúbrica suelta en la portada de la obra y, de no tener datos complementarios, nos quedará la duda sobre si se trata del copista, el compositor o simplemente un propietario (sin olvidar que a veces una misma persona puede compartir estos roles).

En el caso de la música vocal tenemos otro problema, comentado en parte al principio de este apartado: es necesario verificar si la mano que anotó el texto de la obra es la misma que copió la música. En principio, cuando un grupo de fuentes comparte la misma caligrafía musical y textual, y entre ambas se aprecia un trazo similar y un mismo tipo de tinta, resulta lógico suponer que el copista de la música y el texto es uno solo. Si esto no parece concluyente, una comparación detallada entre algunos grafemas que son comunes a ambos lenguajes, como los números arábigos occidentales, puede contribuir a reforzar o

36 JARVIS, 2007: 95, 101-104, 107, 128. Sin embargo, más adelante (p. 199) usará las plicas para diferenciar las manos de Bach y su esposa.

37 GINZBURG, 1994: 138-141. 
descartar tal suposición (por ejemplo, un "3" puede figurar tanto al inicio de una estrofa como en la cifra indicadora de una pieza). Así mismo, los títulos de los movimientos y las indicaciones de tempo (alemanda, preludio, allegro, etc.) normalmente son realizados por la misma mano que copia la música y pueden ser comparados con el texto de la obra propiamente tal.

Si podemos afirmar de manera convincente que los copistas de la música y el texto son uno y el mismo, entonces lo más lógico sería comparar su caligrafía con la de documentos autógrafos que se conserven en los archivos y puedan ser vinculados con el contexto más cercano a la obra. ${ }^{38}$ Podrá objetarse que la caligrafía de un sujeto puede cambiar, por ejemplo, entre una declaración jurada y el texto que escribe en un villancico, dado que este último suele ser más cuidado y se ajusta a espacios predeterminados; pero también es cierto que, si realmente se trata de la misma mano, alguna similitud relevante debería existir entre ambos. Otra objeción señala que, aun cuando tal similitud exista, el hecho de que un documento lleve la firma de un sujeto no necesariamente implica que fue copiado íntegramente por él, sobre todo si se trata de documentación administrativa: con bastante frecuencia los recibos o informes eran redactados por un escribano y el músico se limitaba a firmar. ${ }^{39}$ Por lo tanto, habría que verificar incluso si la firma presenta similitudes con la caligrafía del documento en general a fin de prevenir posibles errores.

Finalmente, aun cuando no logremos identificar al copista, como ocurre quizás en la mayor parte de los casos, su individualización suele ser suficiente para vincularlo con una institución, un período, un tipo de repertorio y/o un grupo humano, que puede incluir tanto a músicos como a personas pertenecientes a otros campos, con lo cual puede llegar a constituir una pieza clave para penetrar en la cultura musical que nos interesa conocer.

\section{LOS COPISTAS Y LA CIRCULACIÓN DE MÚSICA EN LA HISTORIOGRAFÍA DE LA MÚSICA COLONIAL}

Si en las páginas anteriores hemos podido comprobar la existencia de un corpus bastante importante de estudios sobre copistas en relación con la música centroeuropea y española, en el caso de la música colonial latinoamericana éstos ocupan un rol marginal. Entre los pocos trabajos que les otorgan cierta importancia se encuentran los de Bernardo Illari, Javier Marín y Ana Luisa Arce..$^{40}$ En su tesis doctoral, el primero utiliza la caligrafía de varios músicos presentes en el archivo de la catedral de Sucre como argumento complementario para apoyar o descartar algunas atribuciones; además, esta evidencia le sirve para

38 Un ejemplo se halla en la tesis de Rodríguez, quien utiliza las cartas que el copista Francisco Lizondo envió al compositor Miguel de Irízar para caracterizar su caligrafía -RODRÍGUEZ, 2003: 222.

39 Un caso extremo es el de Johann Sebastian Bach, pues se sabe que empleaba un secretario y que éste incluso firmaba algunos documentos en su nombre. Esto parece explicar la gran variedad de firmas que se han atribuido al compositor y hace imposible saber cuáles son realmente suyas -véase JARVIS, 2007: 160.

$40 \mathrm{He}$ tomado conocimiento sobre el estudio caligráfico que Evguenia Roubina incluye en su libro sobre Jerusalem cuando este artículo se hallaba en proceso de edición -véase ROUBINA, 2004: 1-24. 
proponer hipótesis en torno a la circulación de dos obras - "Los afectos convoquen” y "Es Fénix, pues en el nido" - que habrían sido enviadas desde Potosí y Lima, respectivamente. ${ }^{41}$ El propio Illari, en un trabajo más reciente, identifica a Martin Schmid como copista de algunas obras para teclado conservadas en el Archivo Musical de Chiquitos y utiliza evidencia caligráfica para proponer que la así llamada "Misa de Potosî”, atribuida a Zipoli y conservada en Sucre, constituye un pastiche compilado a partir de dos fuentes chiquitanas, "tal vez muchos años después de la muerte del autor". ${ }^{42}$ Una orientación similar tiene el tercer capítulo de la tesis de Marín, quien señala la existencia de obras en las catedrales de México y Puebla que fueron realizadas por copistas activos en España durante los siglos XVII y XVIII, como el ya citado Francisco Lizondo, Juan Pérez, Cayetano Echeverría y Juan de Ledesma. ${ }^{43}$ Sin perjuicio del valor de estos aportes, el estudio de Arce es realmente el único dedicado íntegramente a los copistas de música: se trata de un catálogo que identifica a 206 copistas de la región de Moxos, aprovechando su rara costumbre de firmar los trabajos que realizaban; desafortunadamente para nuestro caso, la época en la que estuvieron activos -fundamentalmente fines del siglo XIX y el siglo XX- los distancia bastante de la presente investigación. ${ }^{44}$

Frente a este magro panorama, la información publicada sobre la circulación musical en el período colonial resulta considerable y la encontramos ya en trabajos de larga data. Por ejemplo, sabemos gracias a Andrés Sas que en 1613 la catedral de Lima decidió encargar a Sevilla una colección de libros de canto "para que se celebrasen los oficios en la dicha Santa Iglesia, porque los libros que ahora había como era notorio eran muy viejos...", ${ }^{45}$ Perdomo Escobar señala que hacia 1632 se conservaban en el Archivo de la catedral de Bogotá libros de Morales, Guerrero, Victoria y Palestrina;4 y Stevenson afirma que los tratados teóricos de Pietro Cerone y Andrés Lorente, impresos en Nápoles y Alcalá de Henares respectivamente, eran bien conocidos en el Perú colonial. ${ }^{47}$

Sin embargo, los estudios que tienen al tópico de la circulación musical como el foco principal de investigación son algo más recientes. En el ámbito de la colonia americana en general, cabe mencionar el de Jania Sarno, por ser quizás de los primeros que intentaron aprovechar fuentes del Archivo General de Indias para explorar la circulación de libros e instrumentos entre España y el Nuevo Mundo. De ahí provienen varias de las referencias sobre el tema que suelen citarse en los últimos años, como aquella de las treinta guitarras y trece vihuelas que fueron enviadas en 1523 a San Juan de Puerto Rico y Santo Domingo. ${ }^{48}$ Así mismo, son relevantes los trabajos de María Gembero a partir de fuentes del mismo archivo, en los cuales ha proporcionado información novedosa, especialmente sobre la circulación de músicos. ${ }^{49}$

En cuanto al virreinato del Perú y, especialmente, a los vínculos musicales entre su capital y otras ciudades, los estudios específicos son aun más recientes. En un trabajo publicado en el año 2004, examiné

41 ILLARI, 2001: 37-42, 249, 338, 402, 556.

42 ILLARI, 2011: 144, 349. Agradezco al autor el haberme permitido consultar este trabajo antes de su publicación.

43 MARÍN LÓPEZ, 2007: 465-506.

44 ARCE, 2011: 151-288.

45 SAS, 1970: 184.

46 PERDOMO ESCOBAR, 1963: 38.

47 STEVENSON, 1959: 58.

48 SARNO, 1986: 100-101.

49 Entre otros, GEMBERO USTÁRROZ, 2000, y GEMBERO USTÁRROZ, 2007. 
la influencia musical de Lima en el Santiago colonial, prestando una atención especial al arribo de instrumentos y músicos. Allí documenté, entre otras cosas, la presencia en Santiago de dos músicos limeños: el notable organero Baltasar Fernández de los Reyes y el también organero y organista mercedario Francisco Marieluz. ${ }^{50}$ Estos datos fueron ampliados y complementados en otro trabajo que publiqué al año siguiente..$^{51}$ Un tiempo después apareció un artículo que enfocaba el tema de un modo algo diferente, pues intentó, por medio de la comparación, establecer similitudes entre prácticas e instrumentos de Lima y el Santiago colonial. Aun sin establecer conexiones musicales directas entre ambas ciudades, este trabajo aportó algunos documentos de interés, siendo quizás el más relevante una copia de las ordenanzas del gremio de carpinteros de Lima de 1575, en las cuales se describe el oficio de "bigolero" o constructor de instrumentos. ${ }^{52}$ Mientras que estos tres trabajos emplearon documentación diversa y hasta cierto punto fragmentaria, en uno más reciente utilicé la serie completa de registros de aduana conservada en el Archivo Nacional Histórico para conocer mejor el proceso de importación desde Lima a Santiago de instrumentos destinados a particulares, en la segunda mitad del siglo XVIII, intentando mostrar cómo estos datos ponían en evidencia ciertos mitos musicológicos en torno a las supuestas repercusiones que la llegada de la república había tenido en Chile..$^{33}$

Pero, si bien estos trabajos constituyen aportes relevantes al tema, salta a la vista que ninguno de ellos ha considerado a la fuente musical como evidencia del proceso de circulación de música en el virreinato peruano, lo que representa otra paradoja de esas tan frecuentes en musicología. En este sentido, la reivindicación realizada por Juan Carlos Estenssoro en 1985, sobre la necesidad de comparar las obras del "Archivo limeño con otros archivos musicales americanos", en gran medida sigue vigente. De hecho, el propio Estenssoro contribuyó con unas pinceladas de los frutos que podía brindar tal ejercicio al advertir cuatro concordancias musicales entre las catedrales de Lima y Santiago, que serán comentadas en el siguiente apartado. ${ }^{4}$

Este artículo asume el desafío planteado por dicho autor y confronta el repertorio conservado en ambas instituciones. Pero a la vez intenta ir más allá, pues su estrategia no solo consiste en comparar obras, sino fuentes musicales en un sentido más amplio, prestando una atención especial a la información que pueda desprenderse de ellas. Al ser los copistas parte esencial de dichas fuentes, la comparación caligráfica se transforma en un medio invaluable para iluminar cuestiones relacionadas con su circulación. ${ }^{55}$ Así, bajo la apariencia de un análisis fundamentalmente descriptivo, lo que se propone es una nueva interpretación de la historia de la música en las instituciones estudiadas y, en un sentido más amplio, de la vida musical en el virreinato peruano durante las últimas décadas de su existencia.

50 VERA, 2004: 116-117.

51 VERA, 2005.

52 ALRUIZ y FAHRENKROG, 2008.

53 VERA, 2010a.

54 ESTENSSORO, 1985: vol. 1, 84.

55 En este sentido, este trabajo amplía y sistematiza una perspectiva metodológica que aparece ya esbozada en los trabajos citados de Rodríguez, Illari y Marín. 


\section{OBRAS CONCORDANTES}

Los fondos musicales a estudiar provienen de catedrales pero se han conservado de manera dispar: mientras el de Santiago se encuentra aún en el archivo catedralicio (en adelante ACS), el de la catedral limeña fue trasladado en algún momento al Archivo Arzobispal de Lima (en adelante AAL). Adicionalmente, estos fondos preservan una parte muy pequeña de lo que debió ser el corpus de obras producidas en ambas instituciones, no solo por la cantidad (unas 450 en ACS y 250 en AAL) sino también por los años que abarcan: aproximadamente de 1770 a 1940 en Santiago y de 1730 a 1830 en Lima. ${ }^{56}$ El marco cronológico de nuestro estudio se ajustará pues al período de intersección entre ambos (1770 a 1830).

Como veíamos unas líneas antes, Juan Carlos Estenssoro identificó en 1985 cuatro concordancias entre el repertorio catedralicio de Lima y Santiago: los villancicos "El orbe entero", "Hermoso imán mío", "Sacros celestes coros" y "Cruel tempestad deshecha", este último atribuido a Antonio Ripa. ${ }^{57}$ Aunque Estenssoro localizó estas concordancias solo a partir de los títulos y por tanto de manera tentativa, recientemente he podido revisar personalmente las copias conservadas en ambos fondos, confirmando que se trata, en efecto, de las mismas obras (véase el detalle en la tabla 1).

Esta revisión me ha permitido también aportar cinco concordancias adicionales: las dos primeras lecciones de difuntos ("Parce mihi domine" y "Taedet animam meam") del compositor español Francisco García Fajer; y los villancicos "Festivos zagales", "No lloren aurora", "Ya que desnudo al raso" y "Hoy al portal ha venido", este último también de Ripa (tabla 1). ${ }^{58}$

Si bien estas concordancias resultan interesantes, no nos permiten decir tanto sobre la circulación musical como podría parecer. Podemos plantear que resulta muy probable que estas piezas fuesen enviadas de Lima a Santiago, considerando la poderosa influencia musical limeña de la cual ya hemos hablado. Al menos en el caso de "Hoy al portal..." el texto lo confirma, pues, como bien observó Claro Valdés, debajo del verso "que vino a Lima el verano" se escribió la palabra "Chile"; 59 es decir, la copia fue realizada en Lima y luego enviada a Santiago, donde se adaptó el texto original. Sin embargo, cabe agregar un dato no menos interesante: en la copia limeña (AAL 28:39) ${ }^{60}$ se aprecia el mismo procedimiento, pues la ciudad de "Cuenca" indicada originalmente fue tachada y cambiada por "Lima". De modo que es posible que la copia fuese realizada en España y posteriormente enviada al Perú. ${ }^{61} \mathrm{Si}$ esto es así, lo que tenemos

56 Hasta el momento, los únicos catálogos de los fondos musicales catedralicios de Lima y Santiago se hallan, respectivamente, en el vol. 2 de ESTENSSORO, 1985, y en CLARO VALDÉS, 1974. Aparte de las cerca de 450 obras catalogadas por Claro Valdés, ha aparecido en los últimos años un número equivalente de obras nuevas del mismo período, que proyecto catalogar a mediano plazo.

57 ESTENSSORO, 1985: vol. 1,84 y vol. 2, 215. Solo las tres primeras fueron mencionadas en su libro publicado a partir de la tesis -véase ESTENSSORO, 1989: 110.

58 De estas concordancias, solo la de las dos lecciones había sido dada a conocer -véase VERA, 2010 b: 351.

59 CLARO VALDÉS, 1974: 10.

60 Las signaturas provienen del catálogo impreso que posee el archivo, el cual, según me ha informado la archivera, Sra. Laura Gutiérrez, fue realizado por Juan Carlos Estenssoro hace algunos años.

61 Cabe señalar que Norberto Almandoz, maestro de capilla de la Catedral de Sevilla de 1939 a ca. 1960, hace constar en un artículo de prensa la existencia allí de una copia de esta obra fechada en 1773 -véase ALMANDOZ: 31-32. Localicé esta referencia con la ayuda de Daniela Maltrain. Sobre Almandoz consulté inicialmente su entrada en Wikipedia. Hay más información en SAGASETA ARISTEGUI, 1999. A pesar de ello, ni "Hoy al portal..." ni "Cruel tempestad..." figuran en el catálogo de música de la catedral sevillana -véase GONZÁLEZ BARRIONUEVO et al., 1994. 
hoy en día es una copia española conservada en Lima y una copia limeña conservada en Santiago. Pero, en las demás obras concordantes, ni el texto ni la música permiten descartar que las copias fuesen enviadas de Santiago a Lima, o que llegasen a ambas ciudades directamente desde España u otro lugar, de manera independiente; sobre todo porque, a medida que Buenos Aires adquirió más y más importancia en el siglo XVIII, no fue infrecuente que los productos enviados de España al puerto limeño del Callao tuviesen a Santiago y Valparaíso como sus intermediarios. ${ }^{62}$

Las concordancias identificadas arrojan también nueva luz sobre las autorías de estas piezas. "Hoy al portal ha venido" figura sin atribución en Santiago y fue catalogado como villancico anónimo por Claro Valdés, pero ahora sabemos que es de Ripa. Por otro lado, la versión limeña del villancico "Festivos zagales" pone en entredicho la atribución a José Antonio González, maestro de capilla en Santiago de 1812 a $1839 .{ }^{63} \mathrm{O}$ la pieza fue compuesta por González y enviada a Lima, donde se omitió su autoría; o bien fue escrita en Lima por un autor no identificado y luego enviada a Santiago, donde, voluntaria o involuntariamente, iba a ser atribuida a él. Esto último parece probable pero, una vez más, con la sola concordancia musical no es posible asegurarlo.

Otro aspecto que dejan entrever las concordancias es la importante circulación del villancico. ${ }^{64} \mathrm{De}$ hecho, de las nueve obras concordantes solo una pertenece a otro género (el oficio de difuntos). En este sentido, debo admitir que me ha resultado sorprendente -aun considerando el carácter fragmentario de la música conservada- no haber encontrado concordancias, por ejemplo, de magníficats, misas o salmos, sobre todo porque compositores representados en ambos fondos, como Melchor Tapia o el propio Ripa, cultivaron estos y otros géneros en lengua latina.

Finalmente, la presencia de García Fajer y Ripa en la tabla 1 confirma la importante circulación de la música española en el virreinato peruano, ya apuntada por Estenssoro en relación con las obras del Archivo Arzobispal de Lima. ${ }^{65}$

\section{INDIVIDUALIZACIÓN Y COMPARACIÓN}

Si nos quedáramos con las concordancias de obras este artículo debiese terminar aquí, con una breve sección de conclusiones. Pero nuestro objetivo es ir un poco más allá y verificar si dichas concordancias indican o no un traspaso de piezas entre ambas instituciones. Si el lector ha leído atentamente las últimas páginas probablemente piense que la evidencia histórica disponible es suficiente para inferir que es así.

62 VERA, 2010b: 352.

63 Sobre González véase VERA y CABRERA, 2011: 708-709.

64 Para efectos de este trabajo, considero como villancico toda pieza no litúrgica con texto sacro en lengua vernácula, independientemente de su estructura musical. Cabe señalar que el término "cantada", que en el siglo XVIII designa algunas obras de este tipo que tienen secciones italianizantes (recitativo y aria), solo figura entre las piezas mencionadas en "El orbe entero", y no en la copia original, sino en una reducción más tardía realizada probablemente por el músico Bonifacio Llaque, cuyo nombre fue anotado en la portada como propietario. Además, esta pieza no tiene secciones italianizantes sino la estructura tradicional de estribillo y coplas. Sobre el villancico y sus variantes véase KNIGHTON y TORRENTE, 2007.

65 ESTENSSORO, 1989: 115. 
En realidad ocurre todo lo contrario: estas concordancias, si bien son relevantes, representan una mínima parte de la música conservada en ambos fondos; en otras palabras, considerando los nexos documentados entre Lima y Santiago, resulta sorprendente y hasta contradictorio que hayamos encontrado únicamente nueve obras en común. Una de las hipótesis de este trabajo es que un estudio detallado de las fuentes musicales y sus copistas permitirá dilucidar en parte esta cuestión.

Como en otras ocasiones, el punto de partida para tal indagación se encuentra en el catálogo de Claro Valdés y, más específicamente, en su observación a un "Trisagio a la Santísima Trinidad” conservado en Santiago (ACS 82): "Sin duda proviene del Archivo Arzobispal de Lima por su carátula enmarcada y adornada, como abundan en dicho Archivo" (figura 1). ${ }^{66}$ La afirmación es correcta, pues exactamente el mismo tipo de carátula se encuentra en varias fuentes limeñas, como, por ejemplo, el villancico "No es privilegio de gracia” de Domingo Arquimbau (figura 2). ${ }^{67}$ Sin embargo, la correspondencia no acaba ahí, pues el copista de ambas obras es también el mismo, como muestra una comparación entre algunos de los rasgos caligráficos más llamativos de estas dos fuentes, tanto textuales como musicales (tabla 2). Cabe puntualizar que la mano que copia la música y el texto es también una sola, como muestra la comparación entre la caligrafía de las indicaciones de tempo y las de la letra de la obra propiamente tal (por ejemplo, la $a$ mayúscula en "allegro" o la $g$ minúscula en "largo"). ${ }^{68}$ El que en adelante llamaré copista I aparece en más de cuarenta obras del Archivo Arzobispal de Lima y solo en cuatro del Archivo de la Catedral de Santiago (tabla 3). ${ }^{69}$ En general, su escritura es extremadamente clara, elegante y de rasgos muy estables, lo que hace relativamente fácil distinguirlo. Algunas de sus características más llamativas se hallan en el modo de escribir algunas letras, el colofón, las claves y el silencio de negra (tabla 2). Su época de actividad queda más o menos delimitada por una "Pasión" de Juan Beltrán fechada en 1806 (AAL 4:1), una misa de Melchor Tapia fechada en 1795 (AAL 33:6) y dos misas del mismo autor fechadas en 1800 (33:10 y 33:11); adicionalmente, el hecho de que copie obras de músicos limeños vincula estrechamente al copista I con la catedral metropolitana. ${ }^{70}$

La tabla 3 incluye referencias a otros seis copistas encontrados en el Archivo Arzobispal de Lima y la catedral de Santiago, con indicación precisa de las fuentes en las cuales los he localizado. La tabla 4 compara su caligrafía en algunas de estas fuentes a fin de mostrar que se trata, efectivamente, de los mismos sujetos. Por razones de espacio he seleccionado solo cuatro símbolos representativos para cada uno, ${ }^{71}$ pero éstos son suficientes para evidenciar la correspondencia caligráfica. El copista II se caracteriza, entre

66 CLARO VALDÉS, 1974: 13.

67 Véase AAL 2:1. Otras obras con dicha carátula se hallan en AAL 2:2 , 4:1, 29:1, 36:1, 36:10, 36:12, 36:13, 36:14, 36:16, $36: 23,36: 24$ y $36: 41$.

68 Esta es la tendencia predominante en las piezas realizadas por este copista. Una excepción se halla en AAL 28:59, donde la letra fue copiada por otra persona.

69 Además de las obras señaladas en dicha tabla, la mano del copista I figura también en el villancico "Por besar de este fénix las plantas" de Roque Ceruti, que parece no conservarse ya en el AAL. He consultado la fotocopia existente en la Pontificia Universidad Católica de Chile, Instituto de Música, Archivo Samuel Claro, signatura MF 4d. El inventario del fondo atribuye la pieza a José de Orejón y Aparicio, pero la portada original indica la autoría de "Zeruti".

70 Sobre Beltrán y Tapia puede verse SAS, 1972: 35-42, 387-390.

71 El análisis para individualizarlos fue mucho más detallado e incluyó un aspecto fundamental pero imposible de reflejar aquí cual es la visión de conjunto -cf. al respecto JARVIS, 2007: 103. 
otras cosas, por la longitud de sus plicas y silencios de corchea; si bien está representado en varias fuentes del Archivo Arzobispal de Lima, generalmente copia solo la parte de acompañamiento u órgano, por lo que pudo tratarse quizás de un organista. El copista III se caracteriza especialmente por la plica y los corchetes, que en las corcheas y semicorcheas invertidas salen siempre hacia la derecha; curiosamente, una de las obras copiadas por él en Lima (AAL 36:60) concuerda musicalmente con otra de Santiago (ACS 108), pero no es en esta última que se aprecia su mano, sino en otras dos obras no concordantes (tabla 3 ). El copista IV presenta una letra $t$ inicial muy característica y podría tratarse del más antiguo de los siete, ya que el villancico "De Guadaira los molineros" está fechado por él en 1769 (AAL 28:28). El copista V resulta el más complejo de distinguir porque varios de sus símbolos son muy inestables $;^{72} \sin$ embargo, su becuadro, el colofón y el silencio de negra tienden a mantener su aspecto. El copista VI es poco significativo en cuanto al número de fuentes, pero resulta de interés que tanto en Lima como en Santiago su mano esté presente en obras atribuidas a "Zapata" ${ }^{73}$ Finalmente, el copista VII muestra un colofón característico que, en conjunto con otros rasgos, permite distinguirlo fácilmente; además, resulta interesante que las obras de la catedral de Santiago copiadas por él lleven la inscripción "Filomeno" (ACS 270 y 380) y una atribución más específica a “J. M. Filomeno” (ACS 197); todas ellas fueron escritas a posteriori y por otra mano, pero, aun así, podrían indicar que estas piezas las llevó el cantor y violinista José María Filomeno cuando pasó de la catedral de Lima a Santiago, en una fecha aún no precisada. ${ }^{74}$

Pero quizás lo más interesante sea que estas concordancias caligráficas resultan más claras que las concordancias musicales a la hora de establecer el trayecto que siguieron estas piezas. En el caso de los copistas I a V la cantidad de obras encontrada en Lima es tan superior a la hallada en Santiago, que es posible afirmar con fundamento que dichos copistas debieron estar activos en la capital del virreinato, o al menos que las obras copiadas por ellos fueron enviadas a Chile desde allí y no a la inversa. Lo confirma una pasión anónima (ACS 324) que lleva en su portada la inscripción "Lima y Septiembre 8 de [17]99"75 y presenta en algunas partes la mano del copista I, con mínimas variantes. Por cierto, de esta obra se conserva otro ejemplar (ACS 74) que fue íntegramente realizado por un copista no localizado en Lima cuya mano, por el contrario, se halla masivamente representada en el fondo santiaguino (nada menos que en 140 de las 470 carpetas catalogadas por Claro Valdés). ${ }^{76}$ Por lo tanto, lo que parece conservarse en la catedral de Santiago es la versión arribada desde Lima (ACS 324) y la copia realizada por un copista local (ACS 74). En cuanto a los copistas VI y VII, si bien aparecen representados en ambos archivos en igual cantidad, parece muy probable que al menos el segundo trabajase en Lima, dada cierta similitud caligráfica con el copista I.

\footnotetext{
72 Por ejemplo, en AAL 33:13 una parte de "basso cantabile" realizada por el copista V muestra que, en las corcheas invertidas, los corchetes salen indistintamente hacia un lado u otro, incluso en una misma página.

73 Según Estenssoro se trata del presbítero Esteban Zapata, bajonista y cantor activo en la catedral de Lima desde 1706, a quien aún recordaba el músico Toribio del Campo en 1791, en su "Carta sobre la música" -ESTENSSORO, 2001a.

74 Sas señala 1821 como data aproximada -SAS, 1972: 159. No puede descartarse que Filomeno fuese el copista VII, aunque por ahora sea solo una conjetura.

75 Ya advertida por CLARO VALDÉS, 1974: 25.

76 Lo he denominado copista 2, utilizando números arábigos a fin de diferenciarlo del copista II de Lima. Véase al respecto VERA, 2011.
} 
Dentro de las obras listadas en la tabla 3, quizás las más relevantes sean los dos villancicos de Ripa, ya que ambos presentan concordancias de obras y copistas al mismo tiempo. En "Hoy al portal ha venido" (AAL 28:39 y ACS 217), la mano del copista II se aprecia tanto en la fuente limeña como en la santiaguina, aunque en la primera su presencia es marginal, mientras que en la segunda realiza todas las partes de la obra. ${ }^{77}$ Más interesante aun es "Cruel tempestad deshecha" (AAL 28:25 y ACS 268), pues tanto la copia conservada en Lima como la de Santiago fueron realizadas por los copistas I y IV. La comparación entre las partes de cada uno (tabla 5) nos muestra que el copista IV es el principal, pues copió prácticamente todas las de la obra, ${ }^{78}$ duplicando incluso las del segundo coro, como normalmente se hacía al ejecutar este repertorio. Considerando la época en la que ambos copistas estuvieron activos ${ }^{79}$ podemos plantear hipotéticamente que el copista IV copió originalmente la pieza y, varios años después, el copista I sacó duplicados de las partes que no los tenían, ${ }^{80}$ quizás para generar una segunda versión íntegra y enviarla a Chile. Yendo aun más lejos, seis de las obras conservadas en Lima cuya realización he logrado atribuir al copista IV son de Antonio Ripa y una de Francisco Delgado (AAL 10:2). Ambos trabajaron en Andalucía (Sevilla y Cádiz) y vieron llegar sus obras a distintas partes de América. Sabemos incluso que un prebendado de la catedral de Sevilla puso a la venta, a fines del siglo XVIII, 344 obras religiosas de Ripa en latín y romance, por lo cual es posible, como afirma Javier Marín, que en los fondos coloniales americanos se encuentren piezas de este compositor originalmente copiadas en España. ${ }^{81}$ Esto último plantea la posibilidad de que el copista IV no fuese limeño sino español, en cuyo caso sus fuentes conservadas en Lima pudieron llegar desde España; después de todo, veíamos unas páginas atrás que una diferencia caligráfica significativa -como la que existe entre los copistas I y IV-indica a veces un contexto de copia diferente. Si todo esto puede parecer demasiado especulativo, no cabe duda en cambio de que la versión de "Cruel tempestad" conservada en Santiago es íntegramente de procedencia limeña.

\section{IDENTIFICACIÓN}

Como hemos anticipado, los copistas de música muy rara vez se atribuyeron claramente el trabajo realizado. Una excepción en el Archivo Arzobispal de Lima se halla en la portada del villancico "Venid pasajeros" de Roque Ceruti, que lleva la inscripción “copió Joseph de la Cueba”, rubricada (AAL 7:15) ${ }^{82}$

77 Hay además un duplicado del violín 1 que fue sacado por el copista 2 de Santiago.

78 La excepción es el tiple 2 del primer coro, que se conserva por mano de otro copista. Pero parece probable que la versión del copista IV se haya perdido.

79 Probablemente hacia 1769 el copista IV y en torno a 1800 el copista I, como ya se ha explicado.

80 La excepción es la parte de órgano, de la cual se conserva únicamente la versión del copista I. Una vez más, es probable que el ejemplar por mano del copista IV se haya perdido. También es posible que en la versión original no hubiese una parte independiente para el órgano.

81 MARÍN LÓPEZ, 2010: 109. El autor agrega que "Lima conserva los villancicos perdidos de Sevilla". Sin embargo, hemos visto que hay constancia de que el villancico de Ripa "Hoy al portal" aún se conservaba en Sevilla hacia 1958.

82 Esto fue advertido por ESTENSSORO, 1985: vol. 2, p. 101. Cueva trabajó en la capilla de la catedral de Lima hacia 1759-1766 como intérprete de oboe y fagot. 
Desafortunadamente, este no es el caso de los siete copistas cuya caligrafía he localizado en Lima y Santiago, por lo cual su identificación resulta mucho más compleja. Pero, aun así, puedo ofrecer resultados positivos para dos de ellos.

El primero es el copista I. Estenssoro pensó que podía tratarse de Andrés Bolognesi, ${ }^{83}$ maestro de capilla en Lima de 1807 a $1823,{ }^{84}$ pues su firma se encuentra en varias piezas anotadas por dicho copista. ${ }^{85}$ Sin embargo, una comparación entre las fuentes musicales y una serie de documentos autógrafos de varios músicos, conservada en el archivo catedralicio, ${ }^{86}$ muestra que su caligrafía es diferente y que su mano aparece muy excepcionalmente en las obras del Archivo Arzobispal. ${ }^{87}$

Esta misma serie documental permite afirmar, en cambio, que el copista I era José Lobatón, cantor tiple de la catedral de Lima de 1796 a $1823 .{ }^{88}$ La comparación con dos documentos autógrafos suyos de 1807 y 1812 muestra una coincidencia absoluta con dicho copista en términos caligráficos (tabla 6). Además, la rúbrica incluida en la portada de la lección primera de difuntos de García Fajer (AAL 15:3) es también suya; de manera que, a similitud de Joseph de la Cueva, aunque de un modo menos explícito, Lobatón se atribuye la copia de esta obra.

La evidencia caligráfica se ve confirmada por la evidencia histórica. En el documento citado de 1812 Lobatón solicita al cabildo un nombramiento como maestro de capilla sustituto y apunta, entre otros méritos, lo siguiente:

En las solemnidades de esta Santa Iglesia he procurado siempre su mayor lucimiento proporcionándole nuevas óperas [es decir, obras], y contribuyendo con cuanto me ha sido posible en sus Fiestas; y en las que aun gravándome a mí mismo (tanto por el gasto continuo del papel, del cual jamás me he insinuado al mismo Maestro, como de mi trabajo personal, llegando éste muchas veces a ponerme en necesidad de velar, por presentar al siguiente una nueva música) no he perdonado medio alguno para cooperar en su mayor lucimiento.

Testigos de mi actividad en desempeño de la Iglesia lo acreditan las mismas óperas como son Misas, Villancicos, Salmos, etc. con que han sido solemnizadas sus Fiestas por mi celo, y las que patentizaré a V. S. I. si fuese de su superior agrado, y aún necesario para anivelar mi mérito con la justa recompensa que he anhelado.

En la noche de Navidad próxima pasada se oyeron varias en toda la noche a costa de mi afán: a las que reuniré las que actualmente he trabajado en desempeño de la semana Santa próxima de este año; la que adorné con nueve lamentaciones nuevas a mi costa. ${ }^{89}$

83 Refiriéndose a la vigilia de difuntos de Joaquín Ampuero (AAL 1:1 y 1:2) afirma: "se conservan tanto partes de una copia antigua, como la copia de Bolognesi”-ESTENSSORO, 1985: vol. 2, p. 1.

84 SAS, 1972: 46-60.

85 AAL $1: 2,5: 3,33: 3,33: 4,33: 6,33: 8,33: 10,33: 11$ y $33: 13$. 01-1819.

86 Archivo de la Catedral de Lima (ACL), Serie D, legajo 20. Me baso en dos documentos escritos por Bolognesi el 14-

87 La he encontrado solo en un villancico de Ripa titulado "Quién va” (AAL 28:57). La parte de violín 1 fue casi sin duda copiada por Bolognesi, pues coinciden el trazo y la letra $a$ mayúscula, entre otras. Además, escribió el encabezado y un par de indicaciones en la parte de "Alto con clave de tiple".

88 Véase sobre este músico SAS, 1972: 190-195.

89 ACL, Serie D, legajo 20, documento de José Lobatón de 30-04-1812. Véase otra transcripción en SAS, 1972: $192-194$. 
Las alusiones al gasto en papel y las noches en vela confirman que Lobatón debió copiar música regularmente; pero, si esto no fuese suficiente, Sas proporciona un documento de fines de 1816 en el que consta que Bolognesi le pagó 11 pesos y 4 reales "por duplicar papeles” de música durante la consagración del obispo de Cuenca. ${ }^{90}$

El otro que he podido identificar es el copista V. Estenssoro hizo notar que existía una caligrafía común a las obras de Melchor Tapia y Zegarra, cantor y organista en Lima de 1775 a ca. 1818. ${ }^{11}$ La tabla 3 muestra que tenía razón, pues la mayor parte de las obras compuestas por Tapia se conservan por mano de dicho copista. Al estar muchas de ellas escritas en partitura, formato que hasta el siglo XVIII era usado con fines de estudio y especialmente para componer, ${ }^{92}$ es razonable pensar que Tapia y el copista $\mathrm{V}$ eran la misma persona. Así parece ser, en efecto, aunque resulte difícil demostrarlo fehacientemente por la mayor inestabilidad que Tapia presenta en su escritura: con frecuencia dibuja una letra de un modo distinto al acostumbrado sin que parezca haber una razón específica para ello. Aun así, he seleccionado cinco caracteres de un documento autógrafo suyo de $1813,{ }^{93}$ que muestran claras similitudes con fuentes musicales realizadas por el copista V (tabla 7), a quien, conviene recordarlo, hemos atribuido antes la misma inestabilidad detectada en la escritura de Tapia.

Esto resulta de gran interés por cuanto en la catedral de Santiago se conserva una versión del salmo "Laudate Dominum omnes gentes" (ACS 12) atribuida a Melchor Tapia, cuya parte de bajo continuo fue realizada por el copista V. Además, se aprecia en las partes restantes una caligrafía muy similar, que podría deberse a un copista que trabajaba en colaboración con él. En este último caso, pudiera tal vez tratarse del organista y violonchelista Mariano Guapaya, quien trabajaba en la iglesia del Oratorio de San Felipe Neri pero prestaba regularmente servicios en la catedral. Digo esto porque durante la ya mencionada consagración del obispo de Cuenca en 1816, Guapaya fue uno de los músicos a quienes Bolognesi pagó por “duplicar papeles”; además, en un documento de 1819 el propio Guapaya señala a Tapia como uno de sus maestros y ya hemos visto que una similitud caligráfica importante puede denotar una relación entre maestro y discípulo. ${ }^{94}$ Lamentablemente no he podido consultar documentos autógrafos suyos para confirmarlo, pero, fuese o no así, el "Laudate Dominum" conservado en Santiago parece ser otra de las fuentes que proceden íntegramente de Lima.

Otro hecho interesante sucede en la parte de violín 1 del salmo "Dixit Dominus" de Tapia (AAL 33:21), pues la inicia el copista V y la termina el copista I (figura 3). Sin duda, debió ser frecuente que copistas cercanos en el tiempo como Tapia y Lobatón colaborasen entre sí, aunque la colaboración debió consistir generalmente en copiar distintas partes cada uno, antes que en repartirse la copia de una misma parte, como ocurre en dicho salmo.

Finalmente, si hemos visto que en la mayor parte de las catedrales hispanoamericanas y españolas los copistas de música no estaban exclusivamente dedicados a esta función, sino que eran cantores o

90 SAS, 1972: 211.

91 ESTENSSORO, 1985: vol. 2, pp. 4, 24.

92 Véase PELINSKI, 1969: 197, y EZQUERRO, 1998: vol 1, p. 210.

93 ACL, Serie D, legajo 20. El documento no lleva fecha pero fue revisado por el cabildo catedralicio el 5 de mayo de ese año. 94 Sobre Guapaya véase SAS, 1972: 171-173, 211. 
instrumentistas "pluriempleados", ${ }^{95}$ podemos decir ahora que la catedral de Lima no fue una excepción en este aspecto. Sin embargo, parece que estos copistas prestaron servicios en la catedral antes de tener un nombramiento oficial en ella como músicos: según Sas, Lobatón ingresó como cantor tiple en 1796, ${ }^{96}$ pero una de las obras que copió está fechada en 1795 y hay evidencia de que trabajaba en la catedral aproximadamente desde 1788;97 así mismo, Guapaya copió música para Bolognesi en 1816 y tres años más tarde intentó, sin éxito, ingresar en la catedral como violonchelista. Por lo tanto, el oficio de copista debió constituir un mérito relevante para obtener una plaza en la capilla catedralicia, especialmente a ojos de su maestro, quien se procuraba así a un empleado que, además de interpretar la música, podía colaborar con la ardua tarea de escribirla.

\section{CONCLUSIONES: EL VILLANCICO EN LA CATEDRAL DE LIMA EN TORNO A 1800 (O LA IMPORTANCIA DE UN SUJETO “MARGINAL" PARA LA HISTORIA DE LA MÚSICA)}

Una de las contribuciones de este trabajo consiste en haber ampliado nuestro conocimiento acerca de los vínculos entre las fuentes musicales conservadas en Lima y Santiago. Más allá de la identificación de obras o compositores concordantes (como Antonio Ripa o Melchor Tapia), el análisis de los copistas ha permitido señalar con precisión algunas piezas que sin duda fueron enviadas a Chile desde la capital del virreinato. Así mismo, el corpus analizado hace pensar que parte del repertorio español que preserva la catedral de Santiago no llegó allí directamente desde España, sino con Lima como intermediario: así ocurrió al menos con los dos villancicos de Ripa ya comentados. Todo esto amplía la información conocida acerca de la poderosa influencia de Lima sobre Chile hasta comienzos del siglo XIX.

La pregunta sobre qué pasó después requerirá un estudio independiente y su respuesta se verá dificultada por la ausencia de fuentes musicales más tardías en Lima. Podemos aventurar, en base a la información histórica disponible, que su influencia fue disminuyendo, pues desde mediados de dicho siglo, si no antes, la catedral de Santiago comenzó a encargar obras directamente a Europa; ${ }^{98}$ además, una importante modificación estructural como fue la instalación de un gran órgano con vistas a disminuir la presencia de la orquesta se realizó en Santiago en 1850, seis años antes que en la catedral de Lima.${ }^{99}$ Pero esto no es suficiente para afirmar que los vínculos musicales entre ambas ciudades se interrumpieron,

95 Sigo en la terminología a EZQUERRO, 1998: vol. 1, p. 218.

96 SAS, 1972: 190

97 En el documento de 1807 afirma que había servido durante diecinueve años y en el de 1812, coincidentemente, durante veinticinco años. Véase ACL, Serie D, legajo 20.

98 En 1851 arribó una importante colección enviada desde Francia; en 1853 llegó otra desde España; a comienzos de la década del sesenta el compositor romano Giuseppe Clementi envío un grupo de piezas de su autoría por expreso encargo de la Catedral de Santiago; y en 1884 otra importante colección fue comprada personalmente en Italia por el maestro de capilla Manuel Arrieta -véase VERA y CABRERA, 2011: 754-768.

99 Sobre el órgano instalado en Santiago véase CLARO VALDÉS, 1979: 23-29, y IZQUIERDO, 2011. Sobre el órgano instalado en Lima hay información en VÉLIZ CARTAGENA, 2009: 72-78. 
sobre todo si consideramos que la maestría de capilla de la catedral de Santiago entre 1846 y 1864 fue ocupada por el peruano José Bernardo Alzedo. ${ }^{100}$

Más allá de esta jerarquía, que refleja lo que pasaba en términos político-administrativos, lo interesante es constatar que no solo el estudio de un fondo musical central como Lima puede permitirnos conocer mejor un fondo periférico como Santiago, sino también a la inversa. Un ejemplo obvio lo constituyen las piezas que en Lima se conservan incompletas, como los villancicos "El orbe entero" (AAL 36:61), que carece de alto y bajo, o "Ya que desnudo al raso" (AAL 36:68), del cual solo se conservan las partes de alto y tiple, pues en estos casos la copia santiaguina permite completar la obra. Pero también es muy probable que varias de las piezas no concordantes, pero cuya procedencia limeña hemos demostrado a través del análisis caligráfico, formaran originalmente parte de la colección de música de la catedral de Lima y hayan sido enviadas (quizás vendidas) posteriormente a Chile. ${ }^{101}$ Esto podría incluso extrapolarse a otras piezas de la catedral de Santiago cuyos copistas no he logrado precisar, pero parecen claramente ajenos a esta institución: el ejemplo más claro se halla en el salmo "Lauda Jerusalem" de Ripa (ACS 11), cuyo copista resulta excepcional en el fondo santiaguino; esta pieza no se encuentra actualmente en el Archivo Arzobispal, pero es mencionada entre los papeles de música "servibles" que Bolognesi inventarió en 1809; ${ }^{102}$ por lo tanto, la copia conservada en Santiago podría ser la misma que se hallaba en Lima en dicho año. Así mismo, la parte de "acompañamiento para el compás" del villancico "Cruel tempestad...", realizada por el copista IV (tabla 5), claramente debió formar parte de la versión que hoy se conserva en Lima, junto al "acompañamiento para el violonchelo" y el "acompañamiento", también realizados por dicho copista. Por lo tanto, en ciertos casos Santiago parece conservar los originales perdidos de Lima. ${ }^{103}$

Otra contribución de este trabajo es que abre la puerta a estudios más detallados sobre el proceso de recepción de música sacra en Santiago, porque permite distinguir qué modificaciones fueron introducidas por músicos o copistas locales. Por ejemplo, en el citado villancico "Cruel tempestad...” se agregó una letra a San Pedro (ACS 268), mientras que en "Hoy al portal...” el copista 2 duplicó el violín 1 (ACS 217). Modificaciones como la primera pueden dar cuenta de devociones que tenían una particular importancia en el lugar de destino, mientras que la duplicación del violín 1 podría indicar el número de instrumentistas que se consideraba apropiado en Santiago para ejecutar la obra. Un estudio más detallado de este tipo de cambios puede ser fructífero si queremos conocer mejor las particularidades que la interpretación musical tenía en uno y otro sitio.

Pero quizás el aporte más relevante sea que este estudio modifica la visión tradicionalmente aceptada acerca de la vida musical de Lima y su catedral a fines de la colonia. Esto amerita una explicación previa. Estenssoro afirmó en su momento que el repertorio conservado permitía establecer que los últimos años del siglo XVIII y primeros del XIX se habían caracterizado por la "desaparición de obras religiosas

100 Sobre este músico puede verse, entre otros, SARGENT, 1984.

101 En todo caso, la presencia del copista 2 en algunas de ellas implica que debieron llegar a Santiago en las primeras décadas del siglo XIX, pues es la época aproximada en la que estuvo activo este copista -véase VERA, 2011.

102 SAS, 1970: 191. Aunque Ripa pudo componer más de una versión de este salmo, la evidencia presentada en este trabajo hace muy probable que fuese la misma.

103 Parafraseando la afirmación de Javier Marín en relación con Lima y Sevilla. Véase la nota 81. 
no litúrgicas", ya que de 1790 a 1820 aproximadamente no se encontraba "una sola obra sin texto latino". Luego, con la renuncia de Bolognesi en 1823 y la llegada de otros músicos como Julián Carabaillo y Bonifacio Llaque, "ambos vinculados a la vida teatral", habían retornado "a la catedral el género del villancico y las obras cómicas". ${ }^{104}$ Esto se relacionaría con las ideas ilustradas y modernistas que se enquistaron lentamente en la elite colonial a partir de la segunda mitad del siglo XVIII y llevaron a un rechazo hacia las formas populares o afines a lo popular, como el villancico. El brusco retorno del género al llegar la independencia se explicaría no solo por un cuestionamiento a dichas ideas, sino porque había seguido cultivándose en otras iglesias y también como canto popular, pero siempre fuera del ámbito catedralicio. Se trataría, en otras palabras, del período en el cual "se diferenció más que en ningún otro el repertorio de la catedral de sus similares". ${ }^{105}$ Cabe señalar que la bibliografía reciente demuestra que estas afirmaciones siguen considerándose válidas en nuestros días. ${ }^{106}$

Sin perjuicio del carácter fundamental que el trabajo de Estenssoro tiene en su conjunto, el presente estudio modifica radicalmente su interpretación de la historia musical catedralicia en los últimos años de la colonia. No es efectivo que de 1790 a 1820 no existan obras sin texto latino en el repertorio conservado en el Archivo Arzobispal de Lima: podrá no haber ninguna atribuida a compositores de ese período, que es algo muy distinto, pero dicha obras existen en la veintena de villancicos copiados íntegra o parcialmente por José Lobatón, ${ }^{107}$ quien trabajó en la catedral casi exactamente en esos años. El hecho de que se trate de partes sueltas y no de partituras habla de copias que sin duda se usaron para la interpretación, pero hay una evidencia complementaria que lo confirma: en el villancico de Ripa "Para colación" (AAL 28:50) las partes vocales llevan indicadas en la esquina superior derecha los nombres de los cantores y entre ellos figura "Joseph Lobatón"; por lo tanto, él mismo participó en la ejecución de villancicos junto a la capilla musical catedralicia. A esto se agrega que, en el documento citado de 1812, el propio Lobatón menciona entre sus méritos haber proporcionado "villancicos", además de misas y salmos, con lo cual queda claro que el género era importante para la práctica musical catedralicia; e incluso Melchor Tapia, considerado por Estenssoro como el mayor representante de la tendencia a componer música litúrgica latina, afirmaba en 1808 haber compuesto también villancicos. ${ }^{108}$

De todo ello se desprenden varias conclusiones relevantes. Una es que la presencia del género a partir de la independencia representa no un brusco retorno, como afirma Estenssoro, sino la continuación de una práctica no interrumpida, pues el villancico nunca desapareció de la catedral metropolitana. Otra es que si bien las ideas ilustradas pueden haber llevado a una menor tolerancia hacia lo popular en la segunda

104 ESTENSSORO, 1985: vol. 1, pp. 88-91.

105 ESTENSSORO, 1989: 118, 124, 127-128. El autor reitera que Llaque resucitó "la tradición colonial de los villancicos" en ESTENSSORO, 2001b: 733.

106 Baker, citando a Estenssoro, alude al "destierro" de géneros musicales como la comedia y el villancico de los contextos sacros en Lima durante estos años -véase BAKER, 2008: 222.

107 AAL $2: 1,2: 2$, 16:7, 28:25, 28:27, 28:35, 28:36, 28:40, 28:44, 28:53, 28:57, 28:59, 29:1 (con 29:2), 36:39, 36:41, 36:49, 36:52, 36:61, 36:68, 36:70.

108 SAS, 1972: 388 . Obviamente, el hecho de que sus villancicos no se conserven o no lleven atribución podría dar lugar a varias hipótesis, pero no se debe a que no hayan existido. 
mitad del siglo XVIII, ${ }^{109}$ las censuras resultantes nunca implicaron la supresión de las prácticas populares o ajenas a la ortodoxia católica, ni siquiera dentro de las instituciones que supuestamente estaban destinadas a preservarla; en este sentido, la tendencia de la elite dirigente en la época parece haber sido más a controlar que a suprimir, o al menos ese fue el efecto que tuvieron sus prohibiciones. ${ }^{110}$

La tercera y última conclusión nos lleva de vuelta al inicio de este trabajo, pues se relaciona con la importancia que los sujetos marginales o subalternos pueden tener para la construcción de la historia de la música. Y no es que esto represente una novedad en el campo de la historia, pero con frecuencia reducimos la condición de marginal exclusivamente a personas ajenas a las instituciones de la elite dirigente, olvidando que dentro de éstas se desempeñaban también personas que tenían un bajo estatus social o que fueron posteriormente despreciadas por la historiografía, lo que, hablando desde un presente que intenta construir un pasado, viene a ser algo similar. Lobatón apenas es mencionado en los textos sobre la música del Perú colonial y su figura aparece como muy menor en comparación con compositores como Torrejón, Araujo o Ceruti; ${ }^{111}$ tanto así que Sas creyó que exageraba al dar cuenta de sus méritos en 1807, cuando solicitó la maestría de capilla. ${ }^{12}$ La evidencia caligráfica nos muestra que no era así, pues se trata de uno de los principales copistas de la catedral en torno a 1800.

Sin embargo, queda aún una interrogante: ¿qué quiere decir Lobatón cuando afirma que debía proporcionar "nuevas óperas” y "presentar al [día] siguiente una nueva música”? ¿Está refiriéndose exclusivamente al acto de copiar o también al de componer? De no haber realizado previamente un estudio caligráfico como el presente, probablemente hubiésemos pensado -como parece haberlo hecho Sas- que la carta de 1812 era la de un compositor dando cuenta de sus méritos. Esto no es descabellado: considerando que quince de las obras copiadas por Lobatón no llevan atribución, ${ }^{113}$ es muy posible que él mismo haya compuesto algunas de ellas. Eventualmente, éste podría ser otro caso en el que el copista de pronto se convierte en compositor a raíz de algún descubrimiento musicológico, como comentábamos antes a propósito de la controversial hipótesis de Martin Jarvis sobre Anna Magdalena Bach y las suites para violonchelo solo. Fuese o no así, no necesitamos "elevar" a José Lobatón a la categoría de compositor para tomar conciencia de su importancia, pues su estudio como "mero" copista ha resultado inestimable para comprender mejor la historia musical de la catedral de Lima en los últimos años de la colonia, así como los procesos de circulación musical en el virreinato peruano.

109 Tanto Estenssoro como otros autores han relacionado este hecho con la música. Véase BAKER, 2008: 60-64, y DAVIES, 2011: 65.

110 En el mismo sentido, Davies en su trabajo citado busca demostrar que la Iglesia finalmente consintió la religión popular, a pesar de los movimientos reformistas de mediados del siglo XVIII.

111 Por ejemplo, Lobatón no tiene entrada en el Diccionario de la Música Española e Hispanoamericana, quizás uno de los principales parámetros a la hora de estimar la importancia de los músicos en la historiografía musical de la región.

112 "Fue Andrés Bolognesi quien ganó, en buena hora, pues carta tan vanidosa y zalamera no podía surtir efecto favorable en los ánimos de un Cabildo consciente"; y en relación con su carta de 1812 ya citada afirma: "Todo lo dicho por el recurrente puede ser cierto, pero su manera de recordarlo es por demás antipática" -SAS, 1972: 191, 194.

113 AAL 36:1, 36:10, 36:12, 36:13, 36:14, 36:16, 36:24, 36:26, 36:39, 36:41, 36:49, 36:52, 36:61, 36:68, 36:70. Se trata principalmente de villancicos. 


\section{BIBLIOGRAFÍA}

ALMANDOZ, Norberto, "Los reyes magos en la música”, periódico ABC (03-01-1958): 31-32.

ALRUIZ, Constanza, y FAHRENKROG, Laura, "Construcción de instrumentos musicales en el Virreinato del Perú: vínculos y proyecciones con Santiago de Chile", Resonancias, 22 (Santiago de Chile, 2008): 43-62.

ARCE, Ana Luisa, "Archivo musical de Moxos. Catálogo de copistas de música manuscrita”, Piotr NAWROT (ed.), Misiones de Moxos: Catálogos II, Santa Cruz (Bolivia), APAC, 2011: 147-288.

BAKER, Geoffrey, Imposing Harmony. Music and Society in Colonial Cuzco, Durham y Londres, Duke University Press, 2008.

BOORMAN, Stanley, "Sources MS. Introduction”, Grove Music Online, 2001.

BROOK, Barry S., y PAYMER, Marvin E., “The Pergolesi Hand: A Calligraphic Study”, Notes, 38/3 (Middleton, Wisconsin, 1982): 550-578.

CLARO VALDÉS, Samuel, Catálogo del archivo musical de la catedral de Santiago de Chile, Santiago, Universidad de Chile, Instituto de Extensión Musical, 1974.

CLARO VALDÉS, Samuel, "Música catedralicia en Santiago durante el siglo pasado", Revista Musical Chilena, 33/148 (Santiago de Chile, 1979): 7-36.

DAVIES, Drew Edward, "Making music, writing myth", Geoffrey BAKER y Tess KNIGHTON (eds.), Music and urban society in colonial Latin America, Cambridge, Cambridge University Press, 2011: 64-82.

EDGE, Dexter, "Viennese Music Copyists and the Transmission of Music in the Eighteenth Century", Revue de Musicologie, 84/2 (París, 1998): 298-304.

EISEN, Cliff, “The Old and New Mozart Editions”, Early Music, $19 / 4$ (Oxford, 1991): 513-532.

EMERY, Walter, "London autograph of 'The forty-eight"”, Music \& Letters, 34/2 (Oxford, 1953): 106123.

ESTENSSORO, Juan Carlos, Música y sociedad coloniales 1680-1830. Lima y el repertorio de música de su catedral, Tesis de licenciatura, Pontificia Universidad Católica del Perú, 1985.

ESTENSSORO, Juan Carlos, Música y sociedad coloniales. Lima 1680-1830, Lima, Colmillo Blanco, 1989.

ESTENSSORO, Juan Carlos, “Zapata Espina, Esteban”, Emilio CASARES (ed.), Diccionario de la música española e hispanoamericana, Madrid, SGAE, 2001a, vol. 10, 1114-1115.

ESTENSSORO, Juan Carlos, "Perú”, Emilio CASARES (ed.), Diccionario de la música española e hispanoamericana, Madrid, SGAE, 2001b, vol. 8, 726-738.

EZQUERRO, Antonio, La música vocal en Aragón en el segundo tercio del siglo XVII, Tesis doctoral, Universidad Autónoma de Barcelona, 1997.

GEMBERO USTÁRROZ, María, "Las relaciones musicales entre España y América a través del Archivo General de Indias de Sevilla", Gérard BORRAS (ed.), Música, sociedades y relaciones de poder en América Latina, Guadalajara (México), Universidad de Guadalajara, 2000: 128-142. 
GEMBERO USTÁRROZ, María, "Migraciones de músicos entre España y América (siglos XVI-XVIII): estudio preliminar", María GEMBERO USTÁRROZ y Emilio ROS-FÁBREGAS (eds.), La música y el Atlántico: relaciones musicales entre España y Latinoamérica, Granada, Universidad de Granada, 2007: 17-58.

GINZBURG, Carlo, Mitos, emblemas e indicios, Barcelona, Editorial Gedisa, 1994.

GONZÁLEZ BARRIONUEVO, Herminio, AYARRA JARNE, José Enrique, y VÁZQUEZ VÁZQUEZ, Manuel (eds.), Catálogo de libros de polifonía de la catedral de Sevilla, Granada, Junta de Andalucía, Consejería de Cultura, Centro de Documentación Musical de Andalucía, 1994.

GRIER, James, La edición crítica de música. Historia, método y práctica, Madrid, Ediciones Akal S. A., 2008.

HOLST, Spencer, El idioma de los gatos, $2^{\mathrm{a}}$ ed., Buenos Aires, Ediciones de la Flor S. R. L., 1995.

ILLARI, Bernardo, Polychoral Culture: Cathedral Music in La Plata (Bolivia), 1680-1730, Tesis doctoral, The University of Chicago, 2001.

ILLARI, Bernardo, Domenico Zipoli: para una genealogía de la música clásica latinoamericana, La Habana, Fondo Editorial Casa de las Américas, 2011.

IZQUIERDO, José Manuel, El órgano Flight \& Son de la Catedral de Santiago, Tesis de magíster, Universidad de Chile, 2011.

JARVIS, Martin, Did Johann Sebastian Bach write the six cello suites?, Tesis doctoral, Charles Darwin University, 2007.

KNIGHTON, Tess, y TORRENTE, Álvaro (eds.), Devotional Music in the Iberian World, 1450-1800. The Villancico and Related Genres, Aldershot (Hampshire), Ashgate, 2007.

LAIRD, Paul, The Villancico Repertory at San Lorenzo El Real del Escorial, Tesis doctoral, University of North Carolina, 1986.

MARÍN LÓPEZ, Javier, Música y músicos entre dos mundos: la catedral de México y sus libros de polifonía (siglos XVI-XVIII), Tesis doctoral, Universidad de Granada, 2007.

MARÍN LÓPEZ, Javier, "Patrones de diseminación de la música catedralicia andaluza en el Nuevo Mundo (ss. XVI-XVIII)”, Antonio GARCÍA-ABÁSOLO (ed.), La música de las catedrales andaluzas y su proyección en América, Córdoba, Universidad de Córdoba, 2010: 95-132.

MARÍN, Miguel Ángel, Music on the margin. Urban musical life in eighteenth-century Jaca (Spain), Kassel, Reichenberger, 2002.

MENDEL, Arthur, "Recent Developments in Bach Chronology”, The Musical Quarterly, 46/3 (Oxford, 1960): 283-300.

PELINSKI, Ramón, "La polifonía vocal española del siglo XVII y sus formas de escribirla”, Anuario Musical, 24 (Barcelona, 1969): 191-198.

PERDOMO ESCOBAR, José Ignacio, Historia de la música en Colombia, Bogotá, Editorial ABC, 1963.

RAMOS LÓPEZ, Pilar, Feminismo y música. Introducción crítica, Madrid, Narcea S. A., 2003.

RODRÍGUEZ, Pablo L., Música, poder y devoción. La Capilla Real de Carlos II (1665-1700), Tesis doctoral, Universidad de Zaragoza, 2003. 
ROUBINA, Evguenia, El responsorio “Omnes Moriemini” de Ignacio Jerusalem: la primera obra novohispana con obligado de violonchelo y su entorno histórico, México D. F., UNAM, 2004.

SAGASETA ARISTEGUI, Aurelio, “Almandoz Mendizábal, Norberto”, Emilio CASARES (ed.), Diccionario de la música española e hispanoamericana, Madrid, SGAE, 1999, vol. 1, 298-300.

SARGENT, Denise, "Nuevos aportes sobre José Bernardo Alzedo", Revista musical chilena, 38/162 (Santiago de Chile, 1984): 5-45.

SARNO, Jania, "El Tráfico de instrumentos y libros musicales de España al Nuevo Mundo a través de los documentos del Archivo General de Indias de Sevilla: Notas para el comienzo de una investigación”, René DE MAEYER (ed.), Musique et influences culturelles réciproques entre l'Europe et l'Amérique Latine du XVIème au XXème siècle, Bruselas, The Brussels Museum of Musical Instruments, 1986: 95-108.

SAS, Andrés, La música en la Catedral de Lima durante el virreinato, primera parte, Historia General, Lima, Universidad Nacional Mayor de San Marcos, Casa de la Cultura del Perú, 1970.

SAS, Andrés, La música en la Catedral de Lima, segunda parte, Diccionario biográfico de los músicos que actuaron en su capilla de música, Lima, Universidad Nacional Mayor de San Marcos, Instituto Nacional de Cultura, 1972.

STEVENSON, Robert, The Music of Peru. Aboriginal and Viceroyal Epochs, Washington, Pan American Union, General Secretariat of the Organization of American States, 1959.

TOMITA, Yo, “Anna Magdalena as Bach’s Copyist”, Understanding Bach, 2 (Londres, 2007): 59-76.

TORRENTE, Álvaro, Fiesta de Navidad en la Capilla Real de Felipe V, Madrid, Editorial Alpuerto, 2002.

TREITLER, Leo, Music and the Historical Imagination, Cambridge (Massachusetts) y Londres (UK), Harvard University Press, 1989.

TYSON, Alan, "Notes on Five of Beethoven's Copyists", Journal of the American Musicological Society, 23/3 (Berkeley, California, 1970): 439-471.

VÉLIZ CARTAGENA, Nelson Mauricio, Crisis, cambio y modernidad en el Perú republicano; la actividad musical en la Catedral de Lima (1821-1919), Tesis de magíster, Pontificia Universidad Católica del Perú, 2009.

VERA, Alejandro, Música vocal profana en el Madrid de Felipe IV: el "Libro de Tonos Humanos" (1656), Lérida, Institut d' Estudis Ilerdencs, 2002.

VERA, Alejandro, “Las agrupaciones instrumentales en las ciudades e instituciones 'periféricas' de la Colonia: el caso de Santiago de Chile”, Víctor RONDÓN (ed.), Música colonial iberoamericana: interpretaciones en torno a la práctica de ejecución y ejecución de la práctica, Santa Cruz de la Sierra, APAC, 2004: 107-119.

VERA, Alejandro, “A propósito de la recepción de música y músicos extranjeros en el Chile colonial”, Cuadernos de Música Iberoamericana, 10 (Madrid, 2005): 7-33.

VERA, Alejandro, “¿Decadencia o progreso? La música del siglo XVIII y el nacionalismo decimonónico", Latin American Music Review, 31/1 (Texas, 2010a): 1-39. 
VERA, Alejandro, "La proyección de García Fajer en el virreinato del Perú: su Vigilia de difuntos conservada en la Catedral de Santiago de Chile”, Miguel Ángel MARÍN (ed.), La ópera en el templo. Estudios sobre el compositor Francisco Javier García Fajer, Logroño, Instituto de Estudios Riojanos, Institución Fernando el Católico, 2010b: 343-360.

VERA, Alejandro, "El archivo musical de la Catedral de Santiago: una nueva aproximación a su contenido e historia en base a hallazgos recientes", Ponencia presentada en el seminario Por los caminos de la historia: Iglesia de Santiago, 450 años (1561-2011), Santiago, Universidad Internacional SEK, 2011.

VERA, Alejandro, y CABRERA, Valeska, "De la orquesta catedralicia al canto popular: la música religiosa durante el primer centenario de la república”, Marcial SÁNCHEZ GAETE (ed.), Historia de la Iglesia en Chile, Santiago, Editorial Universitaria, 2011, vol. 3, 705-777.

\section{APÉNDICES}

Tablas

\begin{tabular}{|c|c|c|c|c|c|}
\hline Compositor & Título & Género & AAL & ACS & Observaciones \\
\hline Anónimo & Festivos zagales & Villancico & $36: 49$ & $\begin{array}{l}250 \\
301 \\
(244)\end{array}$ & $\begin{array}{l}\text { En ACS la pieza se atribuye al } \\
\text { maestro de capilla de la Catedral } \\
\text { José Antonio González. } \\
\text { El número entre paréntesis con- } \\
\text { tiene contrafacta a la Virgen del } \\
\text { Carmen y del Rosario. }\end{array}$ \\
\hline Anónimo & El orbe entero & Villancico & $36: 61$ & 309 & $\begin{array}{l}\text { Concordancia identificada por } \\
\text { Estenssoro en } 1985 .\end{array}$ \\
\hline Anónimo & $\begin{array}{l}\text { Hermoso imán } \\
\text { mío }\end{array}$ & Villancico & $36: 52$ & $\begin{array}{l}186, \\
299 \\
(31 \\
182, \\
183 \\
239 \\
272)\end{array}$ & $\begin{array}{l}\text { Concordancia identificada por } \\
\text { Estenssoro en } 1985 \text {. } \\
\text { Los números entre paréntesis son } \\
\text { contrafacta a Santo Domingo ( } 31) \\
\text { y la Virgen en sus distintas advo- } \\
\text { caciones. }\end{array}$ \\
\hline Anónimo & No lloren, aurora & Villancico & $36: 60$ & 108 & $\begin{array}{l}\text { En Santiago se conserva sólo la } \\
\text { segunda sección (un dúo) de esta } \\
\text { obra y se la cataloga como "la- } \\
\text { mentación". }\end{array}$ \\
\hline Anónimo & $\begin{array}{l}\text { Sacros, celestes } \\
\text { coros }\end{array}$ & Villancico & $36: 64$ & 85 & $\begin{array}{l}\text { Concordancia identificada por } \\
\text { Estenssoro en } 1985 .\end{array}$ \\
\hline Anónimo & $\begin{array}{l}\text { Ya que desnudo } \\
\text { al raso }\end{array}$ & Villancico & $36: 68$ & 76 & \\
\hline
\end{tabular}




\begin{tabular}{|l|l|l|l|l|l|}
\hline Antonio Ripa & $\begin{array}{l}\text { Cruel tempestad } \\
\text { deshecha }\end{array}$ & Villancico & $28: 25$ & 268 & $\begin{array}{l}\text { Concordancia identificada por } \\
\text { Estenssoro en 1985. }\end{array}$ \\
\hline Antonio Ripa & $\begin{array}{l}\text { Hoy al portal ha } \\
\text { venido }\end{array}$ & Villancico & $28: 39$ & 217 & Anónimo en la versión de ACS. \\
\hline $\begin{array}{l}\text { Francisco } \\
\text { García Fajer }\end{array}$ & $\begin{array}{l}\text { Parce mihi } \\
\text { domine / Taedet } \\
\text { animam meam }\end{array}$ & $\begin{array}{l}\text { Primera y } \\
\text { segunda } \\
\text { lección del } \\
\text { oficio de } \\
\text { difuntos }\end{array}$ & $\begin{array}{l}15: 2, \\
15: 3, \\
15: 4\end{array}$ & 136 & $\begin{array}{l}\text { En Lima se conservan solo las } \\
\text { dos lecciones; en Santiago, el ofi- } \\
\text { cio de difuntos completo. } \\
\text { Hay además una copia de la trom- } \\
\text { pa segunda del oficio de difuntos } \\
\text { en AAL 36:7. }\end{array}$ \\
\hline
\end{tabular}

Tabla 1: obras concordantes entre el Archivo Arzobispal de Lima (AAL) y el Archivo de la Catedral de Santiago (ACS)

\begin{tabular}{|c|c|c|}
\hline Rasgo & AAL 2:1 & ACS 82 \\
\hline Letra $g$ minúscula & & \\
\hline Letra $q$ minúscula & & \\
\hline Letra $v$ mayúscula & & \\
\hline Letra $y$ minúscula & & \\
\hline Colofón & & \\
\hline Corchea invertida & & \\
\hline
\end{tabular}




\begin{tabular}{|l|l|l|}
\hline Llave de Do & & \\
\hline Llave de Fa & & \\
\hline Llave de Sol & & \\
\hline Signo de apertura & & \\
\hline Silencio de negra & & \\
\hline
\end{tabular}

Tabla 2: rasgos del copista I en AAL 2:1 y ACS 82

\begin{tabular}{|c|l|l|}
\hline Copista & \multicolumn{1}{|c|}{ AAL $^{1}$} & \multicolumn{1}{|c|}{ ACS } \\
\hline I & $1: 2,2: 1,2: 2,4: 1,5: 3,15: 3,16: 7$, & $82,103,268,324$ \\
& $28: 1,28: 25,28: 27,28: 35,28: 36$, & \\
& $28: 40,28: 44,28: 53,28: 57$, & \\
& $28: 59,29: 1,29: 2,33: 3,33: 4$, & \\
$33: 6,33: 8,33: 10,33: 11,33: 13$, & \\
& $33: 19,33: 21,36: 1,36: 10,36: 12$, & \\
& $36: 13,36: 14,36: 16,36: 24$, & \\
& $36: 26,36: 39,36: 41,36: 49$, & \\
& $36: 52,36: 61,36: 68,36: 70$ & \\
\hline II & $10: 2,11: 2,11: 3,11: 4,11: 5,11: 6$, & 217 \\
& $15: 1,16: 1,16: 2,16: 4,16: 8$, & \\
& $25: 1,28: 20,28: 23,28: 35,28: 39$, & \\
& $28: 41,30: 1,35: 1$ & \\
\end{tabular}

1 Las fuentes señaladas en esta columna y la siguiente indican la presencia del copista en cuestión, pero no la importancia que tuvo en el proceso de copia. Es decir, no indican si copió toda la fuente o se limitó, por ejemplo, a copiar únicamente el "acompañamiento", como hace casi siempre el copista II. 


\begin{tabular}{|c|l|l|}
\hline III & $\begin{array}{l}7: 3,28: 4,28: 35,36: 60,36: 63, \\
36: 64\end{array}$ & 144,262 \\
\hline IV & $\begin{array}{l}10: 2,28: 25,28: 28,28: 36,28: 42, \\
28: 51,28: 52\end{array}$ & 268 \\
\hline V & $6: 1,6: 2,21: 1,21: 2,26: 3,33: 1$, & 12 \\
& $33: 2,33: 5,33: 6,33: 7,33: 8$, & \\
& $33: 9,33: 12,33: 13,33: 14,33: 15$, & \\
& $33: 16,33: 17,33: 18,33: 20$, & \\
& $33: 21,33: 22,36: 17,36: 22$ & \\
\hline VI & $35: 1$ & 215 \\
\hline VII & $36: 3,36: 5,36: 23$ & $197,270,380$ \\
\hline
\end{tabular}

Tabla 3: concordancias de copistas entre las obras conservadas en Lima y Santiago

\begin{tabular}{|c|l|l|l|l|}
\hline Copista & $\begin{array}{l}\text { Fuentes } \\
\text { utilizadas }\end{array}$ & Rasgo & ACS \\
\hline II & $\begin{array}{l}\text { AAL 10:2 y ACS } \\
217\end{array}$ & $\begin{array}{l}\text { Corchea invertida } \\
\text { (tipo 2) }\end{array}$ & \\
\hline II & $\begin{array}{l}\text { AAL 10:2 y ACS } \\
217\end{array}$ & Llave de Fa & \\
\hline II & $\begin{array}{l}\text { AAL 10:2 y ACS } \\
217\end{array}$ & Negra invertida & & \\
\hline II & $\begin{array}{l}\text { AAL 10:2 y ACS } \\
217\end{array}$ & Silencio de corchea & & \\
\hline III & $\begin{array}{l}\text { AAL 36:60 y ACS } \\
144\end{array}$ & Colofón & & \\
\hline III & $\begin{array}{l}\text { AAL } 36: 60 \text { y ACS } \\
\text { Corchea invertida }\end{array}$ & & \\
\hline
\end{tabular}




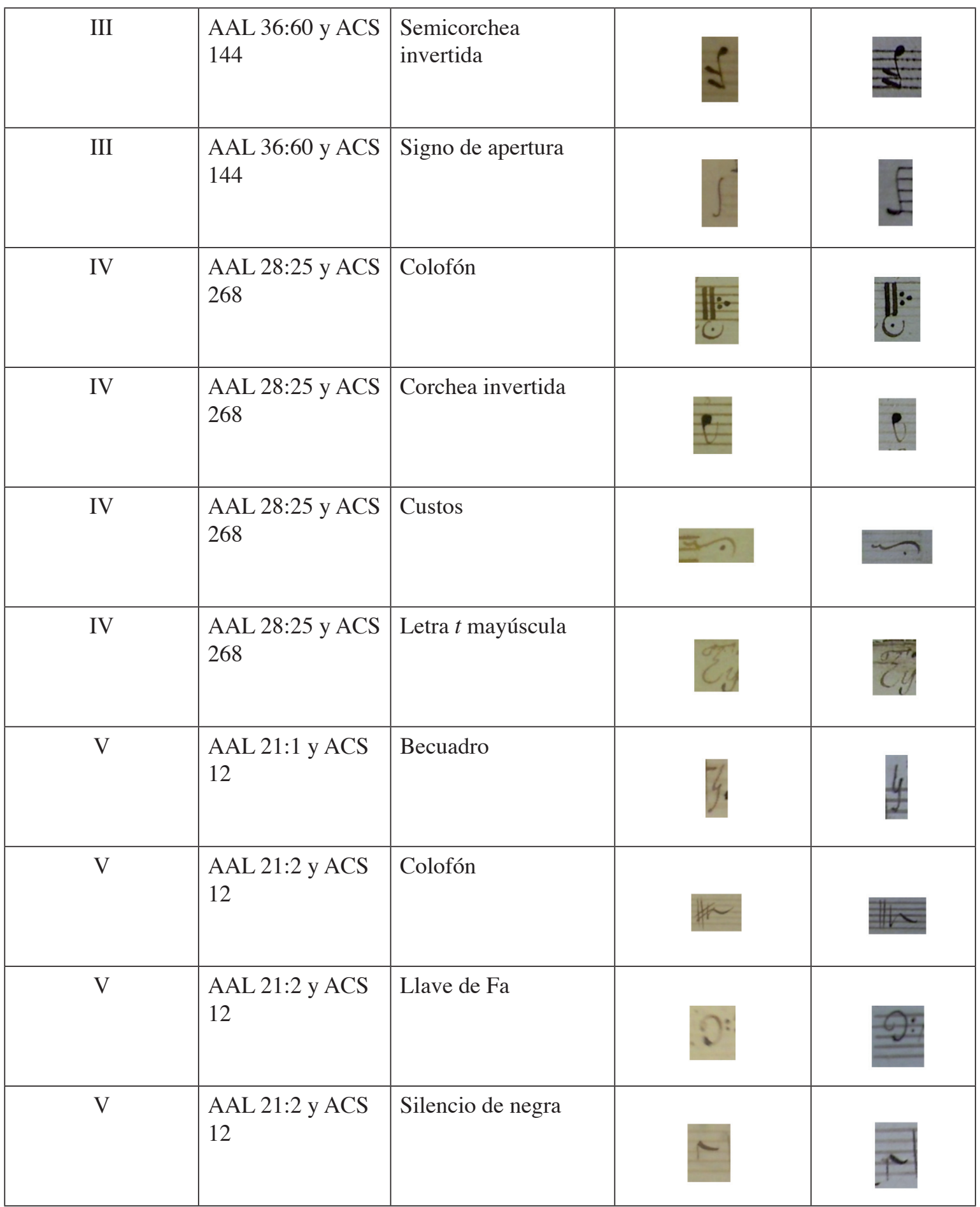




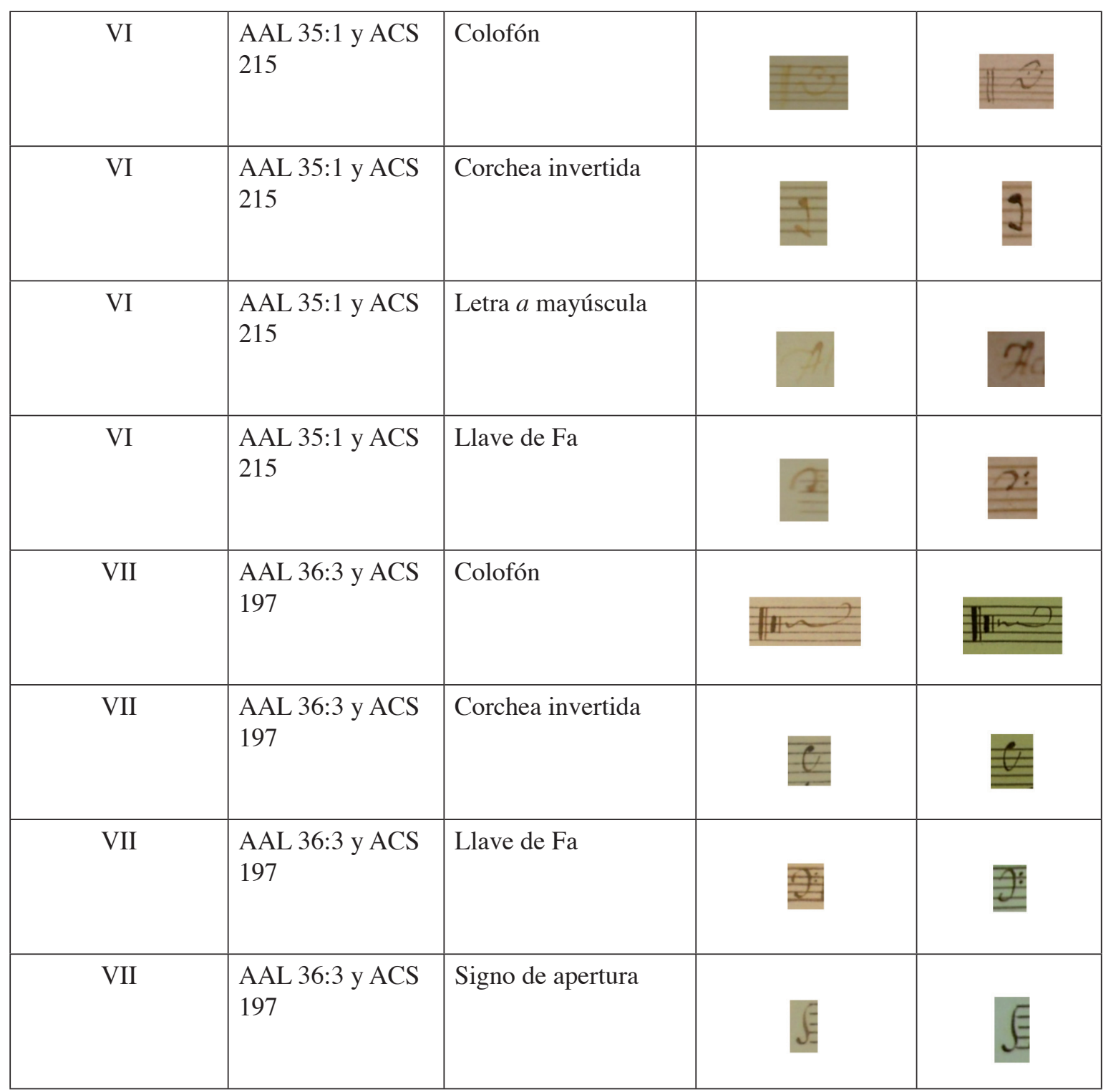

Tabla 4: rasgos de los copistas II a VII en AAL y ACS 


\begin{tabular}{|c|c|c|c|c|}
\hline \multicolumn{3}{|c|}{ AAL 28:25 } & \multicolumn{2}{|c|}{ ACS 268} \\
\hline Copista I & Copista IV & Otro & Copista I & Copista IV \\
\hline \multirow[t]{18}{*}{ Tiple 1} & Tiple 1 coro 1 & & Tiple 1 & \\
\hline & & $\begin{array}{c}\text { Tiple } 2 \text { [coro } \\
1]\end{array}$ & Tiple 2 coro 1 & \\
\hline & Alto coro 1 & & Alto coro 1 & \\
\hline & Bajo coro 1 & & Bajo coro 1 & \\
\hline & Tiple coro 2 & & & Tiple coro 2 \\
\hline & Alto coro 2 & & & Alto coro 2 \\
\hline & Tenor coro 2 & & & Tenor coro 2 \\
\hline & Bajo coro 2 & & & \\
\hline & Violín 1 & & & Violín 1 \\
\hline & Violín 2 & & Violín 2 & \\
\hline & Oboe 1 & & Oboe 1 & \\
\hline & Oboe 2 & & Oboe 2 & \\
\hline & Trompa 1 & & Trompa 1 & \\
\hline & Trompa 2 & & Trompa 2 & \\
\hline & $\begin{array}{l}\text { "Acompañamiento para } \\
\text { el violoncelo" }\end{array}$ & & & \\
\hline & & & & $\begin{array}{l}\text { "Acompañamiento } \\
\text { para el compás" }\end{array}$ \\
\hline & Acompañamiento & & & \\
\hline & & & Órgano & \\
\hline
\end{tabular}

Tabla 5: partes realizadas por cada copista en el villancico "Cruel tempestad deshecha" de Antonio Ripa 


\begin{tabular}{|l|l|c|c|}
\hline Fuentes utilizadas & Rasgo & AAL (música) & ACL (documentos) \\
\hline $\begin{array}{l}\text { AAL 1:2 y ACL, Serie } \\
\text { D, legajo } 20\end{array}$ & Letra $g$ minúscula & & \\
\hline $\begin{array}{l}\text { AAL 1:2 y ACL, Serie } \\
\text { D, legajo 20 }\end{array}$ & Letra $p$ minúscula & & \\
\hline $\begin{array}{l}\text { AAL 1:2 y ACL, Serie } \\
\text { D, legajo 20 }\end{array}$ & Letra $q$ minúscula & & \\
\hline $\begin{array}{l}\text { AAL 1:2 y ACL, Serie } \\
\text { D, legajo } 20\end{array}$ & Letra $v$ mayúscula & & \\
\hline $\begin{array}{l}\text { AAL 1:2 y ACL, Serie } \\
\text { D, legajo 20 }\end{array}$ & Letra $y$ minúscula & & \\
\hline $\begin{array}{l}\text { AAL 15:3 y ACL, Serie } \\
\text { D, legajo } 20\end{array}$ & Rúbrica & & \\
\hline
\end{tabular}

Tabla 6: comparación entre la caligrafía del copista I y la letra del cantor José Lobatón

\begin{tabular}{|l|l|c|c|}
\hline Fuentes utilizadas & Rasgo & AAL (música) & ACL (documentos) \\
\hline $\begin{array}{l}\text { AAL 21:1 y ACL, Serie } \\
\text { D, legajo 20 }\end{array}$ & Letra $d$ minúscula & & \\
\hline $\begin{array}{l}\text { AAL 21:1 y ACL, Serie } \\
\text { D, legajo 20 }\end{array}$ & Letra $f$ minúscula & & \\
\hline $\begin{array}{l}\text { AAL 33:7 y ACL, Serie } \\
\text { D, legajo 20 }\end{array}$ & Letra $g$ minúscula & & \\
\hline
\end{tabular}




\begin{tabular}{|l|l|c|c|}
\hline $\begin{array}{l}\text { AAL 21:1 y ACL, Serie } \\
\text { D, legajo 20 }\end{array}$ & Letra $p$ minúscula & & \\
\hline $\begin{array}{l}\text { AAL 21:1 y ACL, Serie } \\
\text { D, legajo 20 }\end{array}$ & Letra $v$ mayúscula & & \\
\hline $\begin{array}{l}\text { AAL 21:1 y ACL, Serie } \\
\text { D, legajo 20 }\end{array}$ & Letra $y$ minúscula & & \\
\hline
\end{tabular}

Tabla 7: comparación entre la caligrafía del copista V y la letra del organista Melchor Tapia

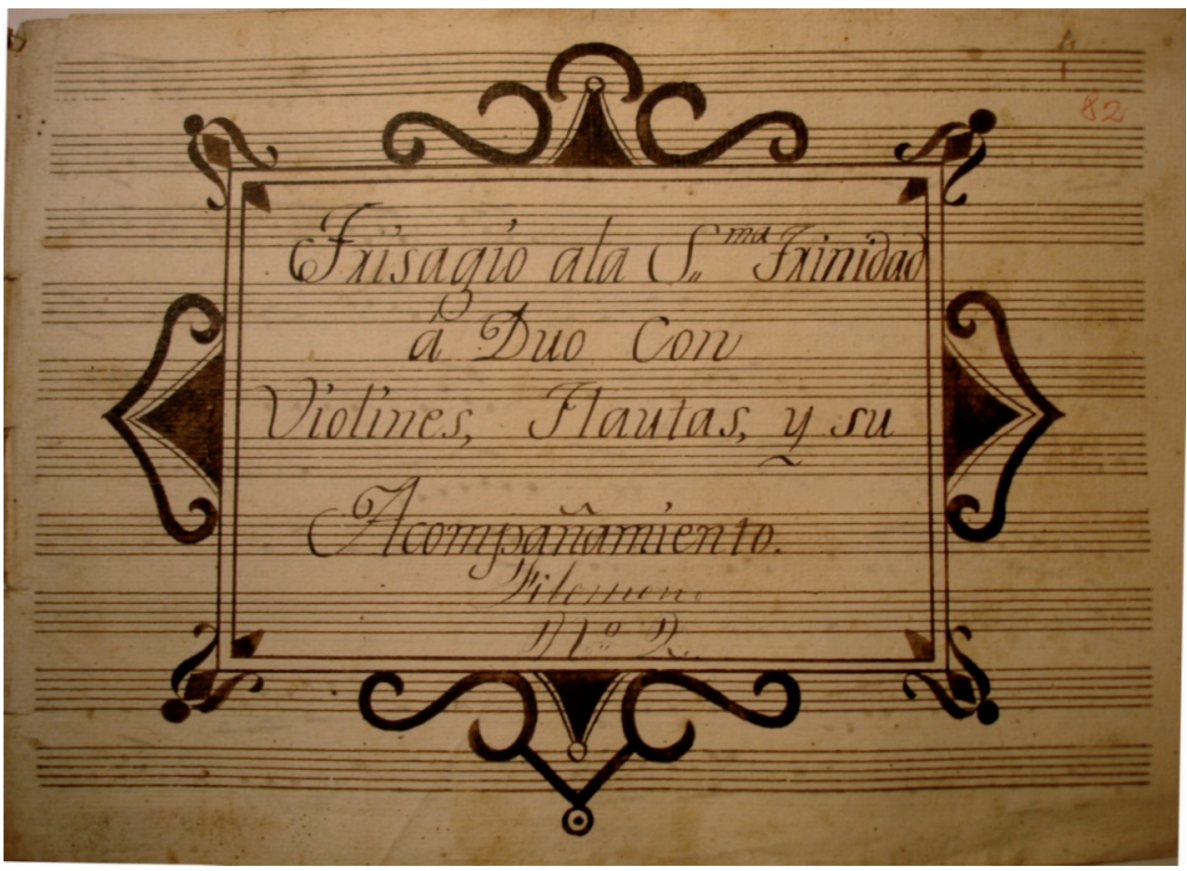

Figura 1. carátula de ACS 82 


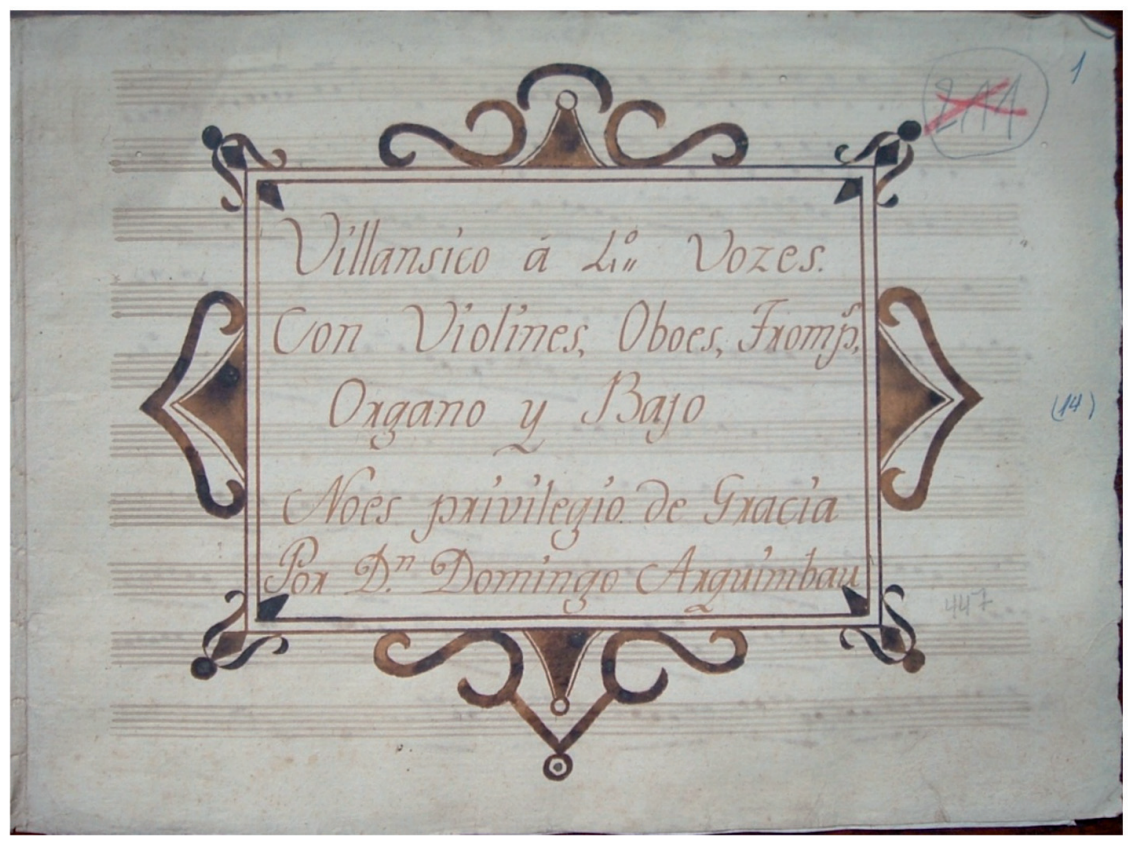

Figura 2. carátula de AAL 2:1

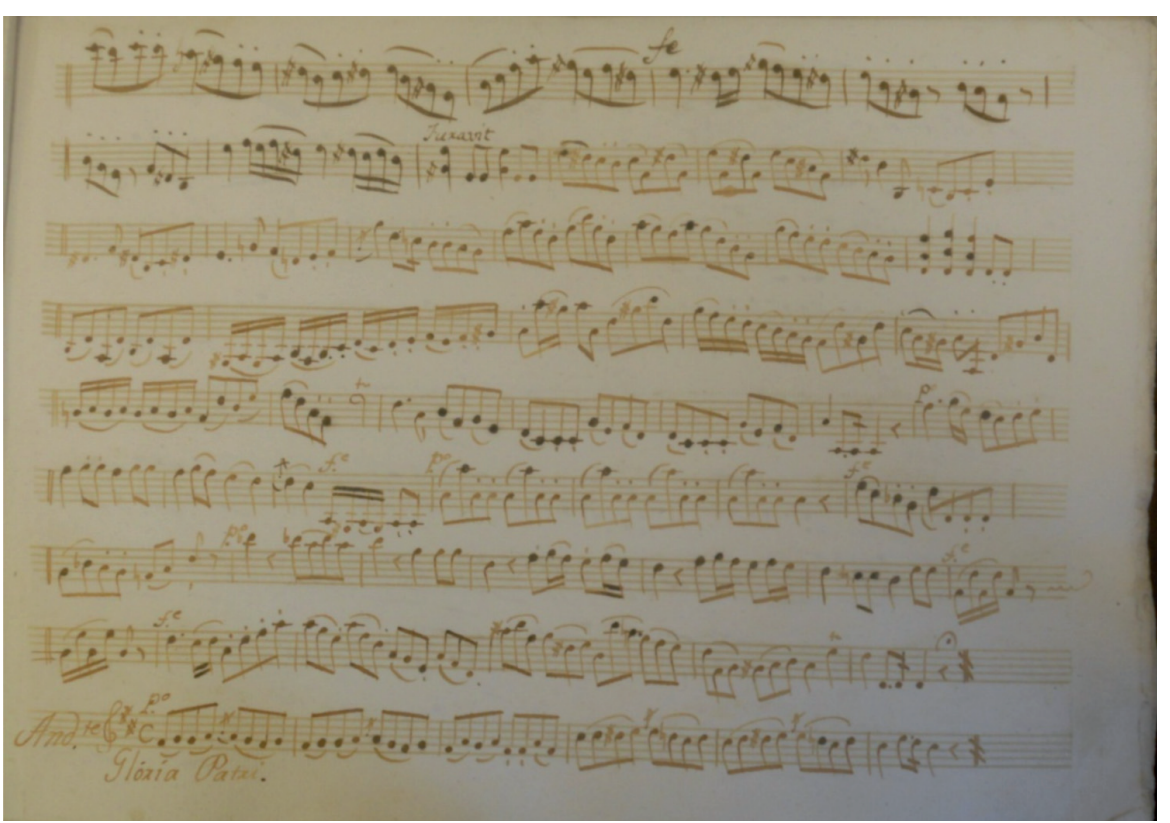

Figura 3. colaboración entre los copistas I y V (AAL 33:21, parte de violín 1)

Recibido: 19/01/2012

Aceptado: 05/03/2012 